\title{
Micropollutants in three tributaries of Lake Constance, Argen, Schussen and Seefelder Aach: a literature review
}

\section{Mikroverunreinigungen in den drei Bodenseezuflüssen Argen, Schussen und Seefelder Aach - eine Literaturstudie}

Rita Triebskorn ${ }^{* 1,2}$ and Harald Hetzenauer ${ }^{3}$

\begin{abstract}
A literature review made evident that in three tributaries of Lake Constance, Argen, Schussen and Seefelder Aach 82 micropollutants (including 3 metabolites of pesticides) were detected in at least one of the streams. Quality standards according to the EU Water Frame Directive (which however comprises only 16 of the detected chemicals) are not exceeded in any of the streams. The comparison of maximal values with existing threshold values and effect concentrations obtained in ecotoxicological analyses and biomarker studies revealed 35 substances to be of relevance in at least one of the three waters. These were 5 chemicals in the Argen, 31 chemicals in the Schussen, and 17 chemicals in the Seefelder Aach, for which effects on mortality, development, health or reproduction in aquatic organisms cannot be excluded.
\end{abstract}

\section{Zusammenfassung}

Eine Literaturstudie ergab, dass in den Bodenseezuflüssen Argen, Schussen und Seefelder Aach insgesamt 82 Mikroverunreinigungen (darunter 3 Metabolite von Pflanzenschutzmitteln) in mindestens einem der drei Flüsse nachgewiesen wurden. Gültige Qualitätsnormen nach der EU-Wasserrahmenrichtlinie, die allerdings nur 16 Stoffe berücksichtigt, wurden in keinem Fluss überschritten. Ein Vergleich der Maximalwerte mit vorliegenden Grenzwerten sowie mit Effektkonzentrationen aus ökotoxikologischen Tests und Biomarkeruntersuchungen erbrachte, dass insgesamt 35 Substanzen in mindestens einem der Gewässer in relevanten Konzentrationen nachgewiesen wurden. In der Argen waren dies 5, in der Schussen 31 und in der Seefelder Aach 17 Spurenstoffe, für die Wirkungen auf z.B. Mortalität, Wachstum, Mobilität, Gesundheitszustand oder Reproduktion von exponierten Organismen nicht auszuschließen sind.

\section{Einführung}

Entsprechend Artikel 4 der EU-Wasserrahmenrichtlinie ist der "gute ökologische und chemische Zustand" der

*Correspondence: stz.oekotox@gmx.de

${ }^{2}$ Steinbeis Transferzentrum für Ökotoxikologie und Ökophysiologie, Blumenstr. 13, 72108 Rottenburg, Germany

Full list of author information is available at the end of the article
Oberflächengewässer ein Umweltziel, das bis 2015 erreicht werden soll [1]. Hierbei soll der Funktion der Gewässer als Lebensraum besondere Aufmerksamkeit gewidmet werden. Vor dem Hintergrund dieser Zielsetzung ist es notwendig, dass Daten zur Präsenz von Umweltschadstoffen und anderweitigen Belastungsfaktoren in Oberflächengewässern mit Informationen zu deren möglicher Wirkung auf die Lebewelt in den 


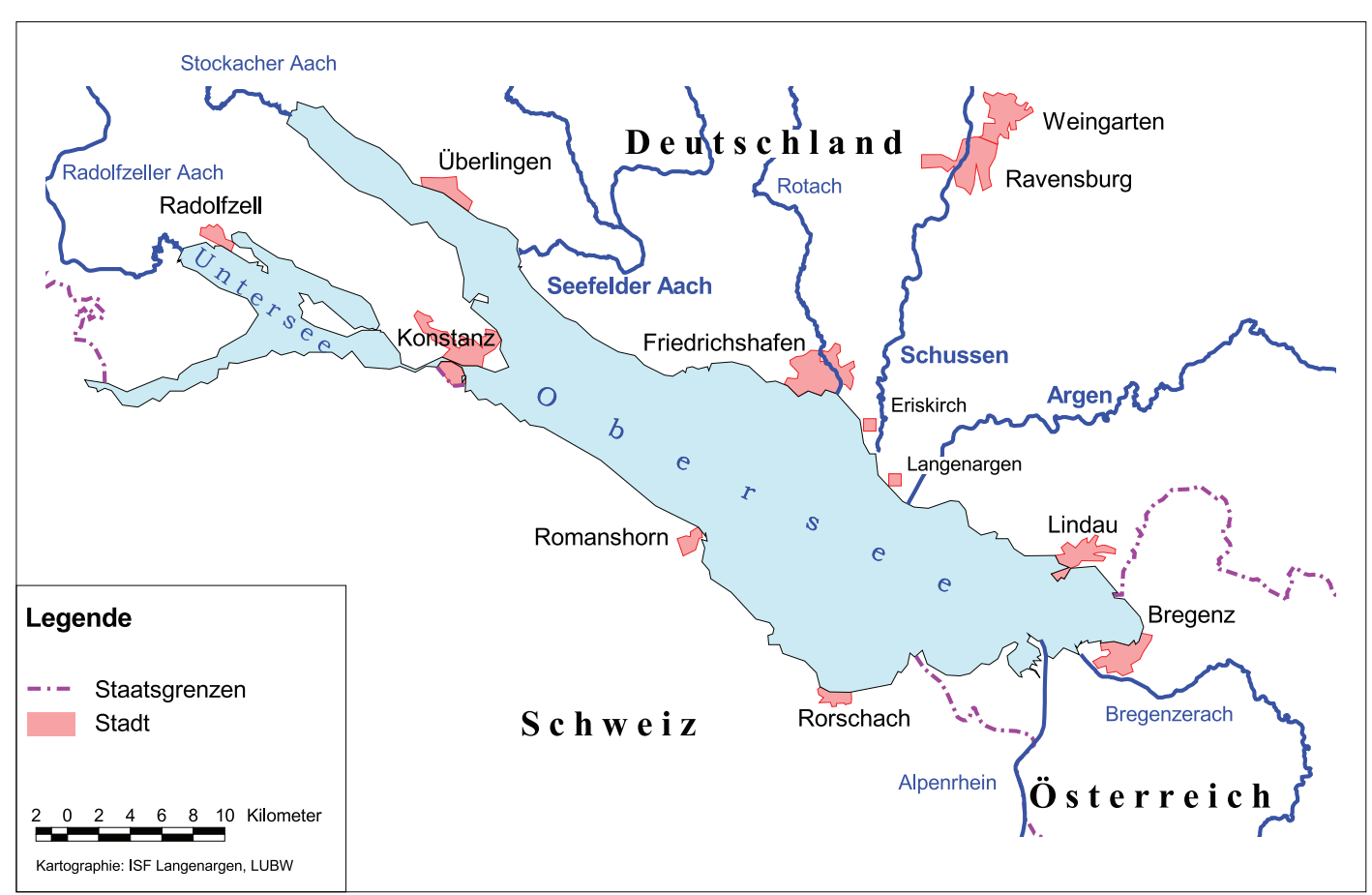

Abb. 1. Lage der drei Bodenseezuflüsse. Übersichtskarte zur Lage der drei Zuflüsse des Bodensees Argen, Schussen und Seefelder Aach.

jeweiligen Ökosystemen zusammengeführt werden. Hierdurch wird es möglich, die Relevanz von Belastungsfaktoren für die ökologische Güte eines Gewässers sowie für die Gesundheit der in ihm lebenden Organismen abzuschätzen.

Im Bereich des Bodensees und seines Einzugsgebiets wurden zahlreiche Untersuchungen zur Belastung der Zuflüsse sowie des Bodensees selbst vor allem mit Nährstoffen durchgeführt. Insgesamt wurde deutlich, dass die Nährstoffkonzentrationen im Bodensee seit Ende der 70er Jahre durch technische Maßnahmen und durch die Einführung von phosphatfreien Waschmitteln drastisch gesunken sind. So liegen die Phosphatwerte im See heute durchschnittlich zwischen 5 und $10 \mu \mathrm{g} / \mathrm{L}$ Gesamtphosphat, die Nitratwerte seit etwa 20 Jahren weitgehend konstant zwischen $0.9-1 \mathrm{mg} / \mathrm{L}$ Nitratstickstoff [2]. Darüber hinaus wurde die Belastung verschiedener Bodenseezuläufe und des Bodensees mit ausgewählten organischen Spurenstoffen und Schwermetallen untersucht. Hierbei zeigte sich, dass mit Ausnahme einzelner kleiner Zuflüsse diese Stoffe meist in sehr geringen Konzentrationen vorliegen, wobei saisonale Spitzen von z.B. Pestiziden durchaus nachgewiesen werden konnten. Auch zur Belastung des Bodenseeeinzugsgebietes mit „neueren Umweltchemikalien“ (Mikroverunreinigungen, Spurenstoffen), z.B. Arzneimitteln, hormonartigen Substanzen, polyfluorierten Tensiden oder Komplexbildnern liegen Messdaten vor, die jedoch bislang noch nicht zusammengeführt wurden. Ziel der vorliegenden Studie war es deshalb, vorhandene Messdaten zu Mikroverunreinigungen in den Bodenseezuflüssen Argen, Schussen und Seefelder Aach als bedeutende Transportwege von Spurenstoffen in den Bodensee zu sammeln, diese vor dem Hintergrund vorhandener Qualitätsnormen und ökotoxikologischer Wirkdaten zu beurteilen sowie auf dieser Basis mögliche Einflüsse auf die Lebewelt in den drei Flüssen abzuschätzen.

\section{Vorgehensweise}

Für drei Zuflüsse des Bodensees (Argen, Schussen und Seefelder Aach) (Abb. 1) wurden aus Berichten und Publikationen Messwerte für Spurenstoffe, die zwischen 1985 und 2007 erhoben wurden, ermittelt und zusammengefasst.

Die Argen ist der drittgrößte Bodenseezufluss mit einem Einzugsgebiet von $653 \mathrm{~km}^{2}$, einer Länge von $78 \mathrm{~km}$ und einem mittleren Abfluss von $20 \mathrm{~m}^{3} / \mathrm{s}$. Im Einzugsgebiet siedeln etwa 85000 Einwohner, deren Abwässer von 9 Kläranlagen gereinigt werden. Das Einzugsgebiet der Schussen beträgt $815 \mathrm{~km}^{2}$, ihr mittlerer Abfluss $11 \mathrm{~m}^{3} / \mathrm{s}$ und ihre Länge $60 \mathrm{~km}$. Mit 200000 Einwohnern und einer Siedlungsfläche von $11 \%$ des Einzugsgebietes ist das Schussengebiet relativ dicht besiedelt. Die Abwässer werden in insgesamt 20 Kläranlagen gereinigt. Die Fließstrecke der Seefelder Aach beträgt $48 \mathrm{~km}$ und 
Tab. 1. Quellenangaben für Mess- und Grenzwerte für die sieben untersuchten Substanzklassen (Pestizide, Arzneimittel, incl. Östrogene und Phytoöstrogene, Industriechemikalien, Komplexbildner, Metalle, Perfluorierte Tenside und Flammschutzmittel

\begin{tabular}{lll}
\hline & Quellen für Messwerte & Quellen für Grenzwerte \\
\hline Pflanzenschutzmittel & {$[2],[3]$} & {$[1],[15],[16],[17],[18],[19],[20],[21],[22],[23],[24],[25],[26]$} \\
Arzneimittel & {$[3],[4],[5],[6],[7],[8]$} & {$[6],[24],[27],[28],[29],[30],[31],[32],[[3],[34],[35],[36]$} \\
Industriechemikalien & {$[3],[6],[8]$} & {$[1],[15],[24],[[30],[31],[37],[38],[39],[40]$} \\
Komplexbildner & {$[4],[5],[8],[9],[10]$} & {$[1],[31],[39],[41],[42]$} \\
Metalle & {$[3]$} & {$[1],[15],[43]$} \\
Perfluorierte Tenside & {$[9],[11]$} & {$[44],[45]$} \\
Flammschutzmittel & $[12],[13], 14]$ & {$[15]$} \\
\hline
\end{tabular}

der mittlere Abfluss ist mit $3,2 \mathrm{~m}^{3} / \mathrm{s}$ deutlich geringer als in der Schussen und Argen. Das Einzugsgebiet beträgt $280 \mathrm{~km}^{2}$. In ihm leben etwa 35000 Einwohner, deren Abwässer in 8 Kläranlagen gereinigt werden. Im Vergleich der drei Flüsse zeigt sich eine abnehmende Belastung aus dem Siedlungsbereich in der Reihenfolge Schussen $>$ Seefelder Aach > Argen und eine abnehmende Belastung aus der ackerbaulichen Nutzung in der Reihenfolge Seefelder Aach $\approx$ Schussen $>$ Argen.

In der Untersuchung wurden die folgenden sieben Substanzklassen berücksichtigt: Pestizide, Arzneimittel incl. Östrogene und Phytoöstrogene, Industriechemikalien, Komplexbildner, Metalle, Perfluorierte Tenside und Flammschutzmittel. Diese sind in Tab. 1 zusammengefasst [1-45].

Für die in den drei Flüssen nachgewiesenen Spurenstoffe wurde in einem ersten Schritt untersucht, ob Qualitätsnormen nach der WRRL [1] bzw. der EU [15] vorhanden sind. Dies war nur für wenige Stoffe der Fall (z.B. für Arzneimittel überhaupt nicht). Darauf hin wurde in der Literatur und in Datenbanken nach formulierten Zielvorgaben recherchiert. Folgende Quellen wurden berücksichtigt: ETOX-Datenbank des Umweltbundesamtes (http://webetox.uba.de/webETOX/index.do), PAN Pesticide- Datenbank (http://pesticideinfo.org/) [16], die Datenbank der U.S. EPA „Ecotox“ (http://cfpub.epa.gov/ ecotox/) sowie die Datenbanken "ULIDAT“ und „UFORDAT“ des Umweltbundesamtes (http://doku.uba. de/) . Information zur Zulassung von Pestiziden wurde der online-Datenbank der BVL (http://www.bvl.bund. $\mathrm{de} /$ ) entnommen.

Die in den Datenbanken enthaltenen Werte basieren in der Regel auf Daten zu akuten und chronischen Standardtests $\left(\mathrm{LC}_{50}, \mathrm{NOEC}\right)$, in Einzelfällen auch auf Resultaten aus Mesokosmosexperimenten. In Zielvorgaben $[\mathrm{ZV}]$ der letzten Jahre sind allerdings teilweise auch bereits Informationen zu endokrinen Wirkungen von Substanzen, die auf Biomarkeruntersuchungen beruhen, eingeflossen. Die in diesen Datenbanken genannten Grenzwerte stammen aus den in Tab. 1 genannten Originalquellen.
In einem weiteren Schritt wurden der ökotoxikologischen Literatur Wirkdaten (NOEC, LOEC, $\mathrm{EC}_{50}$ ) für möglichst viele Vertreter aus den sieben Substanzklassen entnommen.

Auf der Basis der niedrigsten in der ökotoxikologischen Literatur angegebenen Effektkonzentrationen wurden schließlich für diese Substanzen Effekt-basierte Zielvorgaben errechnet. Wenn keine NOEC-Werte vorhanden waren, wurden nach Vorgabe des Technical Guidance Documents der EU LOEC/2-Werte als Substitut verwendet. Als Sicherheitsfaktoren wurden in der Regel (bei Vorhandensein von chronischen Daten zu mindestens drei Arten) 10, bei Vorhandensein von chronischen Daten zu zwei Arten 50, und bei Vorhandensein von chronischen Daten zu nur einer Art 100 eingerechnet.

Für die Abschätzung der ökotoxikologischen Relevanz der Maximalwerte in den Gewässern wurde der geringste Grenzwert (entweder auf der Basis der ökotoxikologischen Studien oder vorhandener Qualitätsnormen) herangezogen. Die Relevanz wurde wie folgt bewertet:

1 Relevanz niedrig (Messwerte $\geq 1 / 3$ des geringsten Grenzwertes)

2 Relevanz mittel (Messwerte < Faktor 3 über geringstem Grenzwert)

3 Relevanz hoch (Messwerte $\geq$ Faktor 3 über geringstem Grenzwert)

\section{Resultate und Diskussion}

Obgleich für die drei Flüsse kein vollständiger Datensatz für alle Chemikalien vorlag, konnten für insgesamt 7 Stoffgruppen (Pestizide, Arzneimittel incl. Östrogen und phytoöstrogene Substanzen, Komplexbildner, Metalle, Industriechemikalien, polyfluorierte Tenside, polybromierte Diphenylether) Messwerte für mindestens ein Gewässer bewertet werden.

Insgesamt wurden 82 Spurenstoffe (davon 3 Metabolite) in mindestens einem der drei Flüsse nachgewiesen. Die maximal gemessenen Konzentrationen dieser Stoffe sind in Tab. 2 zusammengefasst. 
Tab. 2. Maximale Konzentrationen $[\mu \mathrm{g} / \mathrm{L}]$ der nachgewiesenen Stoffe in den drei Testgewässern (Mi: nur Mittelwert vorhanden; PSM: Pflanzenschutzmittel; AM: Arzneimittel)

\begin{tabular}{|c|c|c|c|c|c|c|c|}
\hline & Argen & Schussen & $\begin{array}{l}\text { Seefelder } \\
\text { Aach }\end{array}$ & & Argen & Schussen & $\begin{array}{c}\text { Seefelder } \\
\text { Aach }\end{array}$ \\
\hline PSM: Herbizide & & & & AM: Lipidsenker & & & \\
\hline Atrazin & 0,003 & 0,01 & 0,013 & Bezafibrat & & 0,056 & \\
\hline Desethylatrazin & 0,003 & 0,008 & 0,019 & Clofibrinsäure & & 0,025 & 0,01 \\
\hline Desisopropylatrazin & & & 0,003 (Mi) & AM: Antibiotika & & & \\
\hline 2,4-DP (Dichlorprop) & & 0,07 & 0,23 (Mi) & Chloramphenicol & & 0,04 & \\
\hline Diuron & & 0,068 & $0,11(\mathrm{Mi})$ & Clarithromycin & & 0,07 & \\
\hline Hexazinon & & 0,016 & $<0,001(\mathrm{Mi})$ & Erythromycin & & 0,14 & \\
\hline Irgarol & & & 0,0014 (Mi) & Roxithromycin & & 0,08 & \\
\hline Isoproturon & & & 0,06 & Sulfamethoxazol & 0,05 & 0,2 & 0,03 \\
\hline Mecoprop (MCPP) & & 0,16 & $<0,05$ (Mi) & Trimethoprim & & 0,03 & \\
\hline Metolachlor & 0,001 & 0,003 & 0,002 & AM: Insektenschutzmittel & & & \\
\hline MCPA & & 0,07 & 0,3 & Diethyltoluolamid (DEET) & & 0,048 & \\
\hline Metazachlor & & & $0,02(\mathrm{Mi})$ & AM: Östrogene/Phytoöstrogene & & & \\
\hline Napropamid & & 0,001 & 0,002 (Mi) & 17a-Ethinylestradiol (EE2) & & 0,005 & \\
\hline Pendimethalin & 0,001 & 0,006 & 0,002 & Genistein & & 0,0063 & \\
\hline Simazin & 0,002 & 0,04 & 0,008 & 17-ß-Östradiol & & 0,032 & 0,0007 \\
\hline Terbutryn & 0,002 & 0,017 & 0,01 & Östron & & 0,009 & \\
\hline Terbutylazin & 0,001 & 0,006 & 0,003 & B-Sitosterol & & 1,76 & 0,071 \\
\hline DETA & 0,002 & 0,014 & 0,01 & Industriechemikalien & & & \\
\hline PSM: Fungizide & & & & Benzol & 0,04 & 0,19 & \\
\hline Metalaxyl & 0,001 & 0,004 & 0,003 & Bisphenol A & & 0,41 & 0,0028 \\
\hline Penconazol & 0,001 & 0,004 & 0,003 & Bromdichlormethan & 0,04 & 0,06 & \\
\hline Propiconazol & 0,004 & 0,01 & 0,01 & Di-n-butylphthalat (DBP) & & 0,25 & \\
\hline PSM: Insektizide & & & & 1-2-Dichlorethan & 0,04 & $<0,03$ & \\
\hline Dimethoat & & & 0,01 (Mi) & Dichlormethan & 0,03 & $<0,03$ & \\
\hline Fenitrothion & 0,003 & & & 4-Nonylphenol & & 0,16 & 0,003 \\
\hline Malathion & 0,001 & & & 4-Nonylphenol-diethoxylat (NP2EO) & & 0,066 & 0,006 \\
\hline Pirimicarb & & 0,019 & 0,08 & 4-Nonylphenoxy-essigsäure (NP1EC) & & 1,57 & - \\
\hline AM: Schmerzmittel/Entzündu & emmer & & & 4-Octylphenol & & 0,098 & 0,004 \\
\hline Diclofenac & 0,005 & 0,137 & 0,06 & Trichlormethan & 0,02 & 0,01 & \\
\hline Ibuprofen & & 0,018 & & Tetrachlormethan & 0,04 & 0,01 & \\
\hline Ibuprofen-COOH & & 0,03 & & Tetrachlorethen & 0,01 & $<0,01$ & \\
\hline Ibuprofen-OH & & 0,04 & 0,04 & Komplexbildner & & & \\
\hline Indomethazin & & $<0,019$ & & DTPA & & 124 & \\
\hline Naproxen & & 0,016 & & EDTA & 4,5 & 33 & \\
\hline Pentoxifyllin & & 0,035 & & KPDA & & 34 & \\
\hline Phenazon & & 0,027 & & NTA & 1,2 & 1 & \\
\hline Propyphenazon & & 0,027 & & Metalle & & & \\
\hline AM: Antiepileptika & & & & Blei & 0,2 & 0,2 & \\
\hline Carbamazepin & 0,01 & 0,27 & 0,07 & Cadmium & $<0,1$ & 0,1 & $<0,1$ \\
\hline AM: Beta-Blocker & & & & Chrom & 2 & 2,8 & 2,9 \\
\hline Metoprolol & & 0,01 & & Kupfer & 4,9 & 6,6 & 4,6 \\
\hline AM: Röntgenkontrastmittel & & & & Nickel & 2,4 & 2,3 & 4,2 \\
\hline Diatrizoat & 0,41 & 0,74 & 0,07 & Quecksilber & $<0,05$ & $<0,05$ & \\
\hline lopromid & & 0,08 & & Zink & 9 & 27 & 12 \\
\hline lopamidol & & 0,06 & & Perfluorierte Tenside & & & \\
\hline lotalaminsäure & 0,025 & 0,05 & & PFOA (Perfluoroctanoat) & 0,001 & 0,012 & - \\
\hline \multirow[t]{3}{*}{ loxitalaminsäure } & 0,06 & 0,09 & & PFOS (Perfluorooctylsulfonat) & 0,002 & 0,004 & - \\
\hline & & & & Flammschutzmittel & & & \\
\hline & & & & PBDE & & & 0,000034 \\
\hline
\end{tabular}


Tab. 3. Anzahl der nachgewiesenen Spurenstoffe in den drei Testgewässern jeweils ober- und unterhalb von aus Datenbanken entnommenen Grenzwerten [ZV] aufgeschlüsselt nach Substanzgruppen (PFT: Perfluorierte Tenside; PBDE Polybromierte Diphenylether); -: keine Daten vorhanden

\begin{tabular}{|c|c|c|c|c|c|c|}
\hline & $\begin{array}{c}\text { Argen } \\
<\text { ZV }\end{array}$ & $\begin{array}{c}\text { Argen } \\
\geq Z V\end{array}$ & $\begin{array}{c}\text { Schussen } \\
<Z V\end{array}$ & $\begin{array}{c}\text { Schussen } \\
\geq \mathrm{ZV}\end{array}$ & $\begin{array}{l}\text { Seefelder } \\
\text { Aach }<\text { ZV }\end{array}$ & $\begin{array}{l}\text { Seefelder } \\
\text { Aach } \geq Z \text { ZV }\end{array}$ \\
\hline Arzneimittel und östrogenartige Stoffe & 6 & 0 & 19 & 10 & 8 & 1 \\
\hline Komplexbildner & 2 & 0 & 1 & 3 & - & - \\
\hline Metalle & 4 & 1 & 4 & 2 & 3 & 1 \\
\hline Pflanzenschutzmittel & 11 & 2 & 14 & 4 & 16 & 5 \\
\hline PFT & 2 & 0 & 2 & 0 & - & - \\
\hline
\end{tabular}

Laut EU Richtlinie 2000/60/EG [15] und WRRL [1] werden 33 Substanzen als prioritäre Spurenstoffe eingestuft. Von diesen 33 prioritären Stoffen wurden 16 Substanzen in Argen, Schussen und/oder Seefelder Aach nachgewiesen (Atrazin, BDPE, Benzol, Blei, Cadmium, 1,2-Dichlorethan, Dichlormethan, Diuron, Isoproturon, Nickel, Nonylphenol, Octylphenol, Simazin, Trichlormethan, Tetrachlorethen, Tetrachlormethan). Zusätzlich wurden vier Stoffe gefunden, die einer Überprüfung zur möglichen Einstufung als "prioritäre Stoffe" oder „prioritäre gefährliche Stoffe" $\mathrm{zu}$ unterziehen sind (Bisphenol A, EDTA, Mecoprop, PFOS). Von diesen insgesamt 20 Substanzen gelten drei Stoffe (PBDE, Cadmium und Nonylphenol) als „prioritäre, gefährliche Stoffe [15].Gültige Qualitätsnormen nach der EU-WRRL [1], die allerdings nur 16 Stoffe berücksichtigt, waren in keinem Fluss überschritten. Nach Erhalt der Druckversion dieses Manuskriptes wurde am 31.1.2012 ein Vorschlag der EU zur Fortschreibung der WRRL veröffentlicht mit jetzt 48 prioritären Spurenstoffen und strengeren Grenzwerten. Die Bewertung der Daten ist vor diesem Hintergrund zu überarbeiten.

In der Argen wurden insgesamt 35 Stoffe, in der Schussen 70 und in der Seefelder Aach 38 Substanzen gefunden. Die Zuordnung zu den einzelnen Stoffgruppen ist ebenfalls Tab. 2 zu entnehmen. Von den nachgewiesenen Substanzen lagen in der Argen 32, in der Schussen 45 und in der Seefelder Aach 29 Substanzen in Konzentrationsbereichen weit unterhalb von Konzentrationen, für die laut Informationen aus Datenbanken biologische Effekte zu erwarten sind. In der Argen lagen die Konzentrationen von 3, in der Schussen von 24 und in der Seefelder Aach von 9 Substanzen nahe bei oder über aus Datenbanken entnommenen bereits formulierten Grenzwerten (Abb. 2, Tab. 3). Diese waren: Argen: Fenitrothion, Kupfer, Malathion.

Schussen: Bisphenol A, Cadmium, Carbamazepin, Chloramphenicol, Clarithromycin, Diclofenac, Diuron, DTPA, EDTA, EE 2 , Erythromycin, KPDA, Kupfer,

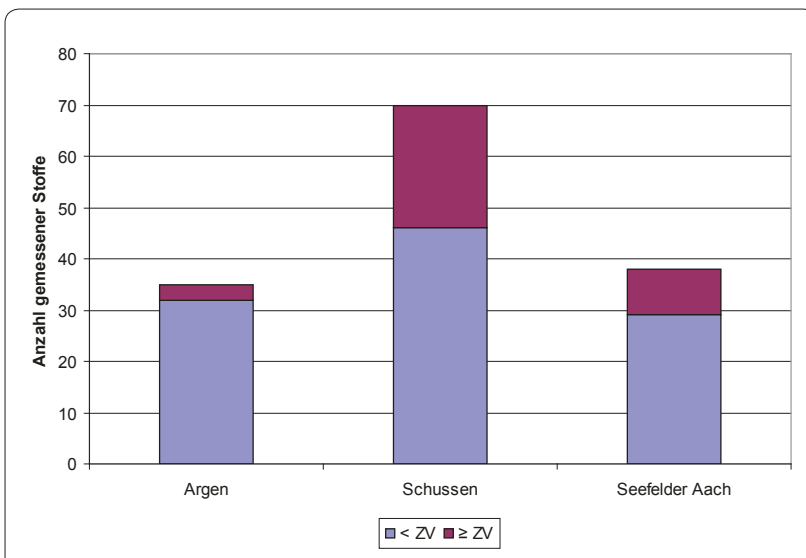

Abb. 2. Anzahl der nachgewiesenen Schadstoffe in den drei Testgewässern. Zusammenfassung der in den drei Flüssen nachgewiesenen Anzahl an Spurenstoffen jeweils oberhalb und unterhalb von aus Datenbanken entnommenen Grenzwerten (ZV).

Mecoprop, 4-Nonylphenol, 4-Nonylphenoxyessigsäure, 4-Nonylphenol-diethoxylat, 4-Octylphenol,17-ß-Östradiol, Östron, Propiconazol, ß-Sitosterol, Sulfamethoxazol, Zink.

Seefelder Aach: Bisphenol A, Diuron, 2,4-DP, Kupfer, MCPA, 4-Nonylphenol, 17-ß-Östradiol, Pirimicarb, Propiconazol.

\section{Pflanzenschutzmittel}

An Pflanzenschutzmitteln wurden in den drei Gewässern insgesamt 22 Wirkstoffe plus 3 Metabolite nachgewiesen. Von diesen haben 8 der gefundenen Herbizide, 3 der nachgewiesenen Fungizide und 2 insektizide Wirkstoffe noch eine Zulassung. DETA ist ein Abbauprodukt des zugelassenen Terbutylazins. 9 nachgewiesene Wirkstoffe haben derzeit keine Zulassung mehr in Deutschland für den Einsatz in der Landwirtschaft (Atrazin, Diuron, Hexazinon, Irgarol, Metolachlor, Simazin, Terbutryn, Fenitrothion, Malathion plus zwei Abbauprodukte des nicht mehr zugelassenen Atrazin), finden aber teilweise 
Tab. 4. Maximalkonzentrationen der von Schlichtig et al. [47] und Rott \& Schlichtig [48, 104] in der Seefelder Aach gemessenen Werte im Vergleich zu den 2007 nachgewiesenen Maximalkonzentrationen dieser PSM [3, 105].

\begin{tabular}{|c|c|c|c|}
\hline & Maximalwerte $(\mu \mathrm{g} / \mathrm{L})$ 1999/2000/2003 & Maximalwert $(\mu \mathrm{g} / \mathrm{L}) 2007$ & Tendenz \\
\hline \multicolumn{4}{|l|}{ Herbizide } \\
\hline Atrazin & 0,12 & 0,01 & $\downarrow$ \\
\hline Bromoxynil & 0,21 & Nicht analysiert & $?$ \\
\hline Chlortoluron & 0,1 & $<B G$ & $\downarrow$ \\
\hline Dichlorprop-P & 3,65 & Nicht analysiert & $?$ \\
\hline Diuron & 0,23 & $0,11^{*}$ & $\downarrow$ \\
\hline Fenoxaprop-P & 0,04 & Nicht analysiert & $?$ \\
\hline Isoproturon & 1,45 & 0,06 & $\downarrow$ \\
\hline loxynil & 0,14 & Nicht analysiert & $?$ \\
\hline MCPA & 0,18 & 0,3 & $\uparrow$ \\
\hline Mecoprop (MCPP) & 0,17 & $<B G$ & $\downarrow$ \\
\hline Metazachlor & 0,18 & 0,02 & $\downarrow$ \\
\hline Metolachlor & 0,11 & 0,002 & $\downarrow$ \\
\hline Simazin & 0,07 & 0,04 & $\downarrow$ \\
\hline Terbutylazin & 0,01 & 0,006 & $\downarrow$ \\
\hline \multicolumn{4}{|l|}{ Insektizide } \\
\hline Pirimicarb & 0,03 & 0,08 & $\uparrow$ \\
\hline \multicolumn{4}{|l|}{ Fungizide } \\
\hline Cyprodinil & 0,04 & $<B G$ & $\downarrow$ \\
\hline
\end{tabular}

noch in Haus und Garten Verwendung und können auf diesem Wege in Gewässer gelangen. Von den nachgewiesenen zugelassenen Wirkstoffen haben, bis auf Napropamid und Penconazol, alle Wirkstoffe noch eine Zulassung für 4-8 Jahre. Die meisten Produkte sind mit dem insektiziden Wirkstoff Dimethoat auf dem Markt.

In der WRRL [1] sowie in der von der EU formulierten Grenzwertrichtlinie EU [15] sind lediglich für vier der in den Flüssen in relevanten Konzentrationen nachgewiesenen Pestizide Grenzwerte formuliert. Dies sind Dichlorprop, Isoproturon als zugelassene sowie Atrazin und Diuron als nicht zugelassene Wirkstoffe. Für alle vier Stoffe liegen die Messwerte unter den Zielvorgaben der WRRL [1] bzw. von EU [15].

Insgesamt gesehen sind die Messwerte für Pestizide für alle drei Gewässer als eher niedrig einzustufen. Sie liegen je nach Wirkstoff, zwischen $0.001 \mu \mathrm{g}$ (Malathion) und $0,2 \mu \mathrm{g}$ (Dichlorprop) und damit maximal in der Größenordnung von, meist jedoch weit unter den PSMKonzentrationen, die z.B. in der Körsch bei Stuttgart gemessen wurden [46].

Von den 25 mindestens in einem der drei Flüsse nachgewiesenen Pestiziden lagen 12 über bzw. in der Nähe der niedrigsten Qualitätsnorm bzw. Zielvorgaben für Oberflächengewässer bzw. aquatische Lebensgemeinschaften, die Datenbanken entnommen wurden. Dies sind Dichlorprop, Mecoprop, MCPA, Isoproturon, Propiconazol, Pirimicarb als zugelassene Substanzen, sowie Atrazin, Diuron, Simazin, Terbutryn, Fenitrothion und Malathion als derzeit nicht zugelassene Substanzen. MCPP wird bei EU [15] gelistet als „Stoff, der einer Überprüfung zur möglichen Einstufung als „prioritärer Stoff“" oder "prioritär gefährlicher Stoff“ zu unterziehen ist". Dies bedeutet, dass mit der Formulierung einer Zielvorgabe auch nach WRRL [1] in naher Zukunft zu rechnen ist.

Hierbei ist insgesamt als problematisch anzumerken, dass je nach gewählten Endpunkten und Zielrichtungen der analysierten Literatur die Zielvorgaben für aquatische Lebensgemeinschaften (AQL) sehr stark differieren. So liegen beispielsweise Zielvorgaben, die endokrine Wirkungen berücksichtigen (z.B. [24]), jeweils um mehrere Potenzen unter den $\mathrm{ZV}$ anderer Autoren, welche Resultate ökotoxikologischer Standardtests als Grundlage für ihre Grenzwerte einsetzen. Die in einer Studie formulierten „kurzfristigen, unbedenklichen Konzentrationen“ für PSM hingegen basieren auf der Auswertung von 41 Monitoring- und Freilandstudien, wobei der Autor davon ausgeht, dass sich aquatische Organismen von Kurzzeitbelastungen wieder erholen können [19].

\section{Historischer Trend für die Einträge von Pflanzenschutzmitteln (Tab. 4)}

Für die Seefelder Aach liegen für Pflanzenschutzmittel Analysedaten ab 1999 vor, so dass Trends für etwa zehn Jahre abgeschätzt werden können. Von [47] wurden 
1999/2000 in der Seefelder Aach 16 PSM nachgewiesen (14 Herbizide, 1 Fungizid, 1 Insektizid). Zwischen 1999/2000 und 2003 wurde von [48] lediglich ein leichter Rückgang der PSM-Belastungen in diesem Gewässer sowie im zusätzlich untersuchten Riedgraben beschrieben. Während im Untersuchungsjahr 1999/2000 58\% der Fließgewässerproben PSM enthielten, war dies für das Jahr 2002 für 52\% der Fließgewässer der Fall. Über den gesamten Untersuchungszeitraum hinweg wurden v.a. zahlreiche Diuronbefunde festgestellt. Die Zielvorgabe AQL für Diuron wurde in der Seefelder Aach 2002 um den Faktor 4 überschritten.

12 der von Rott \& Schlichtig [48] untersuchten Substanzen waren auch im Untersuchungsprogramm 2007 [3], [4] enthalten. Für 10 dieser Substanzen war 2007 eine geringere Maximalkonzentration als im Untersuchungszeitraum 1999/2000 nachzuweisen. Hierzu zählen auch die nach EU als prioritär eingestuften nicht zugelassenen Wirkstoffe Atrazin, Diuron und Simazin sowie der zugelassene Wirkstoff Isoproturon [15]. Zwei Substanzen (MCPA und Pirimicarb, beides zugelassene Wirkstoffe) traten 2007 in höheren Konzentrationen auf als 1999/2000.

Vier Wirkstoffe, die 1999/2000 analysiert wurden (Bromoxynil, Dichlorprop-P, Fenoxaprop-P und Ioxynil), wurden 2007 nicht untersucht. Da es sich bei allen vier Substanzen um zugelassene Wirkstoffe handelt, die in zahlreichen Produkten enthalten sind (10 Produkte mit Bromoxynil, jeweils 7 Produkte mit Dichlorprop-P und Ioxynil sowie ein Produkt mit Fenoxaprop-P), und zumindest Ioxynil in der Vergangenheit über der von Nenzda formulierten Zielvorgabe $(0,1 \mu \mathrm{g} / \mathrm{L})$ lag, sollten diese Wirkstoffe in künftigen Analyseprogrammen berücksichtigt werden [25]. Für Bromoxynil ist darüber hinaus noch von Interesse, dass dieser Wirkstoff in 7 von 10 heute in Deutschland zugelassenen Produkten als Oktanoat enthalten ist. Dieses ist beispielsweise für Daphnien um etwa den Faktor 1000 toxischer als Bromoxynil selbst $\left(\mathrm{EC}_{50}\right.$ Daphnien Bromoxyniloctanoat: 2,5 $\mu \mathrm{g} / \mathrm{L}$; Bromoxynil: $3100 \mu \mathrm{g} / \mathrm{L})$.

\section{Arzneimittel}

Vor ungefähr 15 Jahren tauchten erste Meldungen über Arzneimittelrückstände in Oberflächengewässern auf. Als Reaktion hierauf hat der Bund/Länderausschuss für Chemikaliensicherheit (BLAC) im Auftrag der 53. Umweltministerkonferenz ab 2000 ein umfangreiches Untersuchungsprogramm an etwa 250 Messstellen bundesweit durchgeführt. Dessen Ergebnisse erbrachten, dass die Einträge von Arzneistoffen in Oberflächengewässer nahezu ubiquitär nachzuweisen und in der Summe vergleichbar oder größer denen von Pflanzenschutzmitteln sind [49]. Im Vergleich zu Pflanzenschutzmitteln (Einsatz ca. 30000 t/a) werden an
Humanarzneimitteln jährlich ca. 6500 t, an Veterinärarzneimitteln zusätzlich ca. 1000 t eingesetzt [50].

Mit dem zunehmenden Wissen um die weite Verbreitung von Human- und Veterinärpharmaka in der Umwelt stieg auch das Interesse an möglichen Effekten dieser Stoffe bei exponierten Organismen. Obgleich die Datenlage bis heute bei weitem noch nicht so umfangreich ist wie bei Pflanzenschutzmitteln, wurden doch in den letzten Jahren maßgebliche Arbeiten veröffentlicht, die auch Informationen zu Effekte von Arzneimitteln enthalten [51], [52], [53].

Basierend auf unterschiedlichen Parametern, wie z.B. Verbrauchsmengen, Wirkstoffkonzentration in Oberflächengewässern, chemisch-physikalischen Eigenschaften der Stoffe, Eliminationsraten in Kläranlagen sowie Hinweise auf endokrine Wirkungen wurden an verschiedenen Stellen bisher Prioritätenlisten für Arzneimittel erstellt [29], [54], [55], [56], [57], die in [58] zusammenfassend diskutiert werden.

Zielvorgaben für Arzneimittel sind in der WRRL [1] sowie von der EU [15] nicht enthalten, für acht der nachgewiesenen Stoffe konnten auch der Literatur keine Informationen zu Qualitätsnormen entnommen werden. Diclofenac, Carbamazepin, vier Antibiotika (Chloramphenicol, Clarithromycin, Erythromyzin und Sulfamethoxazol), drei östrogen wirksame Stoffe (17-ßÖstradiol, Östron und $17 \alpha$-Ethinylestradiol) sowie Genistein wurden in Konzentrationen nachgewiesen, die im Bereich von formulierten Qualitätszielen oder Effektkonzentrationen in der Literatur liegen.

Insgesamt gesehen liegen die in den drei Gewässern gemessenen Arzneimittelkonzentrationen für viele Substanzen (Diclofenac, Carbamazepin, Trimethoprim, Clarithromycin) in der Größenordnung von Messwerten für andere Oberflächengewässer. Im Rhein wurden Konzentrationen an Diclofenac von 0,015 - 0,30 $\mu \mathrm{g} / \mathrm{L}$ ermittelt [59], [60], [61]. In der Elbe wurde das Schmerzmittel im Bereich von 0,4 $\mu \mathrm{g} / \mathrm{L}$ nachgewiesen [62]. Carbamazepin wurde im Rhein in Konzentrationen von 0,1 bis 2,1 $\mu \mathrm{g} / \mathrm{L}$ gefunden [59], [61], [63].

Auch die Antibiotika Trimethoprim und Clarithromycin treten in ähnlichen Konzentrationen wie im Rhein bzw. der Wupper auf [64], [65]. Die Werte für die übrigen Antibiotika in der Schussen liegen eher im oberen Bereich der bisher in Oberflächengewässern nachgewiesenen Konzentrationen. So liegen die Konzentrationen von Erythromyzin im Rhein bei 0,005 bis $0,3 \mu \mathrm{g} / \mathrm{L}$ [64], [65]. Als höchste Konzentration in Oberflächengewässern wurde ein Wert von 1,7 $\mu \mathrm{g} / \mathrm{L}$ ermittelt [66], [67], [68]. Von 17 $\alpha$-Ethinylestradiol wurden $0,001 \mu \mathrm{g} / \mathrm{L}$ im Rhein und 0,002 $\mu \mathrm{g} / \mathrm{L}$ im Main nachgewiesen [60]. 17-ß-Estradiol tritt in Oberflächengewässern gewöhnlicherweise bis zu 5,5 ng/L, Östron bis $3,4 \mathrm{ng} / \mathrm{L}$ auf [54]. In der relativ stark über Kläranlagen 
belasteten Körsch bei Stuttgart wurden maximal 0,0018 $\mu \mathrm{g} / \mathrm{L}$ 17-ß-Östradiol und im Mittel $0,3 \mu \mathrm{g} / \mathrm{L}$ $ß$-Sitosterol gemessen [69]. In dem relativ unbelasteten Krähenbach konnte gleichzeitig 17-ß-Östradiol nicht nachgewiesen werden. Der Maximalwert für Östron lag

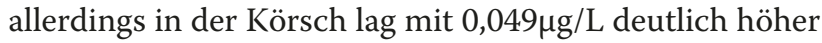
als die in Schussen und Seefelder Aach gemessenen Konzentrationen, im Krähenbach wurden für Östron maximal 0,022 $\mu \mathrm{g} / \mathrm{L}$ nachgewiesen [69]. Generell sind die in der Schussen gemessenen Werte für alle östrogenen Stoffe als relativ hoch einzustufen.

Auch die Konzentration des Phytohormons ß-Sitosterol in der Schussen ist im Vergleich zu Messwerten aus anderen Flüssen, die sich im Nanogramm-Bereich bewegen [60], sehr hoch. Ursache für diese hohe Konzentration in der Schussen kann einerseits der Eintrag aus den Papierfabriken im Oberlauf des Gewässers sein, da Papierfabriken 3 -Sitosterol aus Holzbzw. Recyclingmaterial freisetzen [70]. ß-Sitosterol kommt neben Holz allerdings natürlicherweise auch in Hopfen und Mais vor. Beide Kulturen sind an der Schussen sehr verbreitet, so dass ein Eintrag des Phytohormons z.B. durch Ernterückstände nicht auszuschließen ist. Es wird allerdings auch in Anti-Aging Produkten (z.B. Antifaltencremes) eingesetzt, die nach Körperreinigung ins Abwasser gelangen können, so dass ein Eintrag über Kläranlagen ebenfalls möglich ist.

Insgesamt zeigen ökotoxikologische Untersuchungen, dass sich je nach gewähltem Endpunkt und untersuchter Testspezies die Effektdaten um mehrere Potenzen unterscheiden können. Die beste Datenlage besteht für endokrine Wirkungen nach Expositionen gegenüber östrogenartigen Substanzen.

Für die untersuchten Antibiotika liegt die auf der Basis von ökotoxikologischen Untersuchungen errechnete Zielvorgabe über den der Literatur entnommenen Werten, da diese berücksichtigen, dass die direkte Toxizität dieser Substanzklasse für die aquatische Lebewelt erst im $\mathrm{mg} / \mathrm{L}$ Bereich auftritt, dass aber Bakterien, die über längere Zeit geringen Dosen ausgesetzt sind, Resistenzen entwickeln [71]. Hinweise auf Resistenzbildung von Klärschlammbakterien gegen Erythromycin und Trimethoprim sind beschrieben [72], [73].

Die Schädigung von Organen bei Regenbogenforellen und Karpfen durch Diclofenac und Carbamazepin bedingt die im Vergleich zu bereits formulierten Grenzwerten geringeren $\mathrm{ZV}$ auf der Basis der ökotoxikologischen Untersuchungen [74], [75].

Für $\mathrm{EE}_{2}$ liegt die auf der Basis der ökotoxikologischen Studien errechnete ZV um den Faktor 3 unter, für Östron entsprechend über der formulierten $\mathrm{ZV}$, ansonsten liegen die bereits formulierten und neu errechneten Werte in der gleichen Größenordnung.
Für ß-Sitosterol ist den Datenbanken keine Zielvorgabe $\mathrm{zu}$ entnehmen. Obgleich die östrogene Potenz dieses Phytohormons im Vergleich zu 17-ß-Östradiol oder $\mathrm{EE}_{2}$ eher als gering einzustufen ist, konnte eine Vitellogenininduktion bei männlichen Forellen schon ab $25 \mu \mathrm{g} / \mathrm{L}$ (bei dreiwöchiger Exposition) beobachtet werden [70]. Schon $0,1 \mu \mathrm{g} / \mathrm{L}$ ß-Sitosterol führten bei der Schnecke Lymnaea stagnalis zu histologischen Veränderungen in der Gonade [76]. Die auf der Basis dieser BiomarkerWerte errechnete Zielvorgabe für $B$-Sitosterol läge auf dieser Basis bei $0,01 \mu \mathrm{g} / \mathrm{L}$. Dieser Wert wäre an der Schussen um mehr als den Faktor 100, allerdings auch an der Seefelder Aach um den Faktor 7 überschritten.

Rückstände von Arzneimittelwirkstoffen werden in der Umwelt häufig nicht als Einzelstoffe, sondern im Gemisch mit weiteren Arzneimittelwirkstoffen, deren Metaboliten oder weiteren Xenobiotika nachgewiesen, so dass sowohl antagonistische als auch (über)-additive Effekte auftreten können [33]. Dies ist auch für die drei Testgewässer im vorliegenden Projekt der Fall. Bereits die bisherigen Analysen, die allerdings bei Weitem nicht die Gesamtpalette der potentiell nachweisbaren Arzneimittelwirkstoffe erfassen, machen deutlich, dass sogar innerhalb einer Wirkstoffklasse oftmals mehrere Wirkstoffe in den Gewässern auftreten. Dies ist zum Beispiel für Antibiotika, Schmerzmittel oder östrogenartige Substanzen der Fall. Theoretisch ist somit auf jeden Fall mit Mischungseffekten zu rechnen.

Gezeigt wurde ein überadditiver Effekt eines Stoffgemisches aus Antibiotika (ß-Lactam) und 5-Fluoruracil (Zytostatikum) auf das Wachstum eines Abwasserbakteriums, wobei die Toxizität des Stoffgemisches um mehrere Größenordnungen über der der Reinsubstanzen lag [77]. Eine starke Toxizität einer Mischung aus Diclofenac, Ibuprofen, Naproxen (alle auch in der Schussen vorhanden) und Acetylsalicylsäure wurde bei Daphnien und Algen festgestellt, wobei die eingesetzten Konzentrationen bei den Einzelsubstanzen keine oder nur geringe Effekte zeigten [78]. Eine Untersuchung zur Toxizität von Einzelsubstanzen, die auch in der Schussen nachgewiesen wurden, (u.a. Clofibrinsäure, Erythromycin, Sulfamethoxazol, Trimethoprim) und verschiedenen Stoffgemischen dieser Wirkstoffe (jeweils in Konzentrationen zwischen $10-100 \mu \mathrm{g} / \mathrm{L}$ pro Einzelwirkstoff) bei Daphnia magna [79] zeigte, dass Gemische von Arzneimitteln Wirkungen hervorrufen können, die aus dem Verhalten der jeweiligen Einzelsubstanzen nicht vorauszusagen sind. So stellte man beispielsweise bei dem Gemisch aus Clofibrinsäure $(100 \mu \mathrm{g} / \mathrm{L})$ und Fluoxetin (Anti-Depressivum) $(36 \mu \mathrm{g} / \mathrm{L})$ Mortalitäts- und Missbildungseffekte bei Daphnia magna fest, die durch die Einzelsubstanzen in der gleichen Konzentration nicht hervorgerufen wurden. Während die einzelnen Arzneimittelwirkstoffe Erythromycin, Triclosan und 
Trimethoprim bei Konzentrationen von $10 \mu \mathrm{g} / \mathrm{L}$ keinen Einfluss auf die Entwicklung und das Geschlechterverhältnis von Daphnia magna hatten, wurde durch ein Gemisch dieser drei Wirkstoffe $(30 \mu \mathrm{g} / \mathrm{l})$ der Anteil der männlichen Nachkommenschaft um $20 \%$ reduziert. Obgleich diese Studien die mögliche Mischungstoxizität von Arzneimitteln unzweifelhaft verdeutlichen, muss berücksichtigt werden, dass die eingesetzten Konzentrationen in diesen Untersuchungen weit über den in den drei Flüssen nachgewiesenen Wirkstoffkonzentrationen liegen. Dennoch ist davon auszugehen, dass kombinatorische Effekte auch mit anderen Xenobiotika wahrscheinlich sind und Mischungstoxizitäten auftreten können, die aufgrund von Zielvorgaben auf der Basis von Einzelsubstanzen nicht vorhersehbar sind.

Eine ausführliche Bewertung der Umweltrelevanz von Human- und Veterinärarzneimitteln [33] unterscheidet zwischen Umweltrelevanz (1) aufgrund der chemischen Eigenschaften bzw. des Umweltverhaltens der Stoffe und (2) aufgrund der zu erwartenden ökotoxikologischen Wirkungen. Im Rahmen dieser Studie wurden Humanarzneimittel zunächst in einem ersten Schritt als potenziell umweltrelevant klassifiziert, wenn sie eines der fünf Kriterien (1) Vorkommen im Oberflächenwasser, (2) Vorkommen im Grundwasser, (3) Vorkommen im Trinkwasser, (4) Daten zur Wirkung und (5) Daten zum Umweltverhalten/Abbaubarkeit vorhanden, erfüllten. 92 Wirkstoffe erfüllten mindestens eines dieser Kriterien. Außer Chloramphenicol, Iotalaminsäure und Ioxitalaminsäure sind alle in Argen, Schussen und/oder Seefelder Aach nachgewiesenen Arzneimitteln in der Liste dieser 92 Stoffe enthalten.

Von den mindestens in einem der drei Gewässern nachgewiesen Arzneimitteln gelten laut [33] als umweltrelevant aufgrund ihrer ökotoxikologischen Wirkung: Clarithromycin, Erythromyzin, Sulfamethoxazol, Diclofenac, Carbamazepin und 17 $\alpha$-Ethinylestradiol.

Vom Stockholm County Council [80] wurde ebenfalls 2007 eine Bewertung von Arzneimitteln vorgenommen, die auf (1) Persistenz, (2) Bioakkumulation und (3) Toxizität der Substanzen beruht. Für jeden dieser Bereiche wird einer Substanz eine Bewertung zwischen 1 und 3 zugeordnet. Die Bewertungen für die drei Bereiche werden zusätzlich aufsummiert und den Einzelwerten vorangestellt, so dass eine Gesamt-Klassifizierung von 3 (wenig relevant) bis 9 (hoch relevant) möglich ist. Entsprechend dieses Systems wurde Diclofenac mit 7 $(3+3+1)$, Carbamazepin mit $4(3+0+1)$, Erythromyzin und Sulfamethoxazol mit jeweils $6 \quad(3+0+3)$ und Trimethoprim mit $4(3+0+1)$ bewertet.

\section{Industriechemikalien}

An Industriechemikalien wurden neben chlorierten und bromierten Kohlenwasserstoffen und Benzol die weit verbreiteten Stoffe Nonylphenol, Octylphenol, Bisphenol A und Butylphthalate untersucht. Laut WRRL und EU [1], [15] gelten Benzol, 1,2-Dichlorethan, Dichlormethan, Nonylphenol, Octylphenol, Tetrachlorethen, Trichlormethan, Tetrachlormethan, Nonylphenol und bis(2ethylhexyl)phthalat (DEHP) als prioritäre Stoffe, Bisphenol A gehört zu den Stoffen, die einer Überprüfung zur möglichen Einstufung als "prioritärer Stoff“ oder „prioritär gefährlicher Stoff“ zu unterziehen sind.

Die in der Schussen gemessenen Konzentrationen von BPA liegen mit maximal 0,4 $\mu \mathrm{g} / \mathrm{L}$ eher im oberen Bereich der für andere Gewässer nachgewiesenen Konzentrationen. Im EU-Risk Assessment für BPA sind für den Rhein Mittelwerte zwischen 0,01-0,08 $\mu \mathrm{g} / \mathrm{L}$, für die Elbe Maximalwerte zwischen 0,4- 0,7 $\mu \mathrm{g} / \mathrm{L}$ BPA angegeben. In der relativ stark mit Klärwasser belasteten Körsch bei Stuttgart wurden maximal 0,27 $\mu \mathrm{g} / \mathrm{L} \mathrm{BPA}$, in dem relativ unbelasteten Krähenbach in Parallelmessungen maximal $0,059 \mu \mathrm{g} / \mathrm{L}$ BPA nachgewiesen [69]. Konzentrationen von 4-Nonylphenol bewegen sich generell zwischen $0,028 \mu \mathrm{g} / \mathrm{L}$ für die Elbe und $1,22 \mu \mathrm{g} / \mathrm{L}$ für die Oder [81]. In der Körsch wurden maximal 0,16 $\mu \mathrm{g} / \mathrm{L}$, im Krähenbach maximal 0,45 $\mu \mathrm{g} / \mathrm{L}$ Nonylphenol gemessen [69]. Folglich liegen auch für Nonylphenol die Messwerte in der Schussen mit maximal 0,16 $\mu \mathrm{g} / \mathrm{L}$ im Bereich der üblicherweise in Oberflächengewässern auftretenden Konzentrationen.

Die Konzentrationen von Octylphenol in Schussen und Seefelder Aach sind geringer als die Maximalkonzentration von 0,18 $\mu \mathrm{g} / \mathrm{L}$ in der Körsch [69].

In der Schussen liegen die Konzentrationen von Bisphenol A, 4-Nonylphenol, 4-Nonylphenol-diethoxylat und 4-Nonylphenoxy-essigsäure (NP1EC) deutlich über, die Werte für 4-Octylphenol und Bromdichlormethan in der Nähe der formulierten Zielvorgaben bzw. Umweltqualitätsnormen (UQN) [24], [15], [30]. Auch in der Seefelder Aach liegen die Werte für Bisphenol A und Nonylphenol über, der Wert für Octylphenol in der Nähe dieser Zielvorgaben, wobei die Wirkgrenzen für Bisphenol derzeit kontrovers in der Literatur diskutiert werden [82], [83], [84].

Insgesamt liegen 6 Substanzen über bzw. in der Nähe der geringsten, Datenbanken entnommenen Zielvorgaben (Bromdichlormethan, Bisphenol A, 4-Nonylphenol, 4-Octylphenol, 4-Nonylphenol-diethoxylat, 4-Nonylphenoxy-essigsäure), und nur drei Substanzen über den auf der Basis von ökotoxikologischen Studien errechneten Zielvorgaben (Bisphenol A, 4-Nonylphenol, 4-Octylphenol). Für 4-Nonylphenol-diethoxylat, 4-Nonylphenoxy-essigsäure waren keine Ergebnisse aus Biomarkeruntersuchungen zu finden.

Di-n-butylphthalat wurde in der Schussen in geringer Konzentration nachgewiesen, die weit unterhalb der vorgeschlagenen Zielvorgabe liegt. Dennoch sollte auch 
künftig auf diese Substanz bzw. die Gesamtgruppe der Phthalate geachtet werden, da sie nachgewiesenermaßen anti-androgene Wirkungen zeigen und sowohl bio-, als auch geoakkumulierbar sind, weshalb sie als Stoffgruppe mit hoher Priorität eingestuft werden [85]. Di-2-ethylhexylphthalat (DEHP), das bislang an den drei Flüssen nicht untersucht wurde, ist ein prioritärer Stoff laut WRRL mit einer UQN von $8 \mu \mathrm{g} / \mathrm{L}$.

\section{Komplexbildner}

Die organischen Komplexbildner EDTA (Ethylendiamintetraessigsäure), DTPA (Diethylentriaminpentaessigsäure) und NTA (Nitrilotriessigsäure) bilden mit mehrwertigen Metall-Ionen Chelatkomplexe, die in der Umwelt sehr stabil und gut wasserlöslich sind. Komplexbildner werden aufgrund dieser Eigenschaft in vielerlei Branchen und Produkten eingesetzt (z.B. Metallverarbeitung, Papierindustrie, Textil- und Lederindustrie, Herstellung Waschund Reinigungsmittel, Pharmazeutika und Pflanzenschutzmitteln). Sie gelangen über gereinigtes Abwasser aus Industrie und Privathaushalt in Oberflächengewässer, wo sind im unteren $\mu \mathrm{g} / \mathrm{L}$-Bereich nachweisbar sind. KPDA (Ketopiperazindiacetat) gilt als Abbauprodukt von EDTA, DTPA und möglicherweise auch von NTA [9]. An der Schussen erwiesen sich Milchwerke, Papierindustrie und Textilausrüster als Hauptquellen der EDTABelastung. DTPA wird dort nahezu ausschließlich von zwei Betrieben der Papier- und Zellstoffindustrie eingetragen. Aufgrund der Schließung einer Papierfabrik sowie Einsatz neuer Technologien beim zweiten Werk ist mit einer drastischen Reduktion des Eintrages von Komplexbildnern in der Zukunft zu rechnen.

Das Vorkommen und die Herkunft der Komplexbildner in der Schussen wurden in der Studie aus den Jahren 1999/2000, in der 15 direkt bzw. in einem Fall indirekt in die Schussen einleitende Kläranlagen sowie drei Gewässermessstellen integriert waren [9] sowie in zwei weiteren Studien von 2000 und 2006 untersucht [10], [86].

Die 2006 erhobenen Werte für EDTA entsprechen mit $24 \mu \mathrm{g} / \mathrm{L}$ in der Größenordnung den Werten von 1999, die DTPA Konzentrationen an der Station Lochbrücke haben von im Mittel $34 \mu \mathrm{g} / \mathrm{L}$ auf etwa $61 \mu \mathrm{g} / \mathrm{L}$ zugenommen. Im Jahr 2007 sind noch weit höhere DTPA-Konzentrationen im Bereich der Schussenmündung nachgewiesen worden [10].

Die Zielvorgabe der LAWA für nicht leicht abbaubare Stoffe von $10 \mu \mathrm{g} / \mathrm{L}$ ist deutlich überschritten. Als mögliches Abbauprodukt von EDTA, DTPA und / oder NTA wurde auch KPDA in einer Größenordnung nachgewiesen, die deutlich über dem LAWA-Grenzwert liegt.

Typische Konzentrationen von EDTA, NTA und DTPA in europäischen Flüssen bewegen sich zwischen 0 und $60 \mu \mathrm{g} / \mathrm{L}$ [87], Maximalwerte können bei bis zu $500 \mu \mathrm{g} / \mathrm{L}$ EDTA liegen [88]. Demzufolge liegen die in der Schussen gemessenen Konzentrationen im mittleren bis eher höheren Bereich und überschreiten die formulierten Zielvorgaben deutlich. Die Konzentrationen in der Argen sind als niedrig einzustufen, liegen allerdings in der Nähe der niedrigsten Zielvorgabe.

Die ökotoxikologischen Wirkdaten machen deutlich, dass die untersuchten Komplexbildner auf allen trophischen Ebenen erst Reaktionen im mg-Bereich (ab $1 \mathrm{mg} / \mathrm{L}$ ) zeigen. Hierbei ist Daphnia magna die sensitivste Spezies. In weicherem Testwasser mit geringeren Calciumgehalten war die Toxizität jeweils höher als in härterem Testwasser. Dementsprechend liegen 3 Substanzen (EDTA, DPTA, KPDA) über bzw. in der Nähe der geringsten den genannten Datenbanken entnommenen Zielvorgaben, keine Substanz überschreitet die auf der Basis von Biomarkerstudien errechneten Zielvorgaben. Generell ist jedoch bekannt, dass die Problematik der Komplexbildner weniger auf deren direkter Toxizität als auf indirekter Toxizität in Verbindung mit Metallen sowie auf deren Akkumulierbarkeit in Umweltmedien beruht. So wurde beispielsweise gezeigt, dass die Induktion von Phase-II Biotransformationsenzymen bei Fischen durch Kupfer doppelt so stark in Gegenwart von EDTA induziert werden als wenn Kupfer alleine verabreicht wurde [89]. Laut EU Risk Assessment ist es allerdings eher die Regel, dass die Toxizität von Metallen (außer Quecksilber) durch die Komplexierung mit EDTA 17-1700fach reduziert wird, dass die Toxizität von EDTA selbst allerdings durch die Bindung von Metallen $(\mathrm{Cu}, \mathrm{Hg}, \mathrm{Cd})$ erhöht wird [90]. Metalle können zudem z.B. aus dem Sediment via Bindung an Komplexbildner freigesetzt werden. Aufgrund der weiten Verbreitung der Komplexbildner kommt das EU Risk Assessment trotz der sehr geringen Toxizität von EDTA für aquatische Organismen zum Schluss, dass ein Risiko für die aquatische Umwelt aufgrund der hohen Produktionsmengen und der weiten Verbreitung der Substanz besteht und Risikominderung gefordert ist.

Als Folge dieses Risk Assessments wird EDTA bei der EU als „Stoff, der einer Überprüfung zur möglichen Einstufung als „prioritärer Stoff“ oder „prioritär gefährlicher Stoff“" zu unterziehen ist", gelistet [15].

\section{Metalle}

Oberflächengewässer in Deutschland sind häufig mit Kupfer, Zink und Blei belastet, wobei diffusen Emissionsquellen eine große Bedeutung zukommt [91]. Die starken Emissionen in Umweltkompartimente sind in sog. „umweltoffenen Anwendungen“ dieser Stoffe, wie die Verwendung in Materialien für Dacheinbauten, Regenrinnen, Fallrohre, Kamine, Dachabdichtungen, Fassadenelemente und Verkleidungen begründet. Die für die drei Gewässer vorhandenen Messwerte sind als gering 
einzustufen. Sie liegen deutlich unter den Werten, die in Körsch, Rhein und Elbe gemessen wurden [46].

Außer für Nickel sind die auf Basis der ökotoxikologischen Studien abgeleiteten ZV niedriger als die niedrigsten den Datenbanken entnommenen Grenzwerte. Dies ist vor allem für Kupfer der Fall, das sich im Embryotest mit Zebrabärblingen als sehr toxisch erwies. Diejenigen Stoffe, deren Konzentration über den vorhandenen Grenzwerten liegen, überschreiten auch die ZV auf der Basis der ökotoxikologischen Tests.

\section{Perfluorierte Tenside}

Perfluorierte Tenside (PFTs) sind organische Verbindungen, die bei der Behandlung von Materialoberflächen (z.B. in der Textilindustrie zur Herstellung atmungsaktiver Jacken, in der Papierindustrie zur Herstellung von schmutz-, fett- und wasserabweisenden Papieren) verwendet werden. Eingesetzt werden diese Verbindungen z.B. in der Photoindustrie, bei der Herstellung von Feuerlöschmitteln, Shampoos und Pestiziden sowie in der Luft- und Raumfahrt. Zudem können sie Bestandteil von Schmier- und Imprägniermitteln sein. Perfluorierte Tenside sind in der Umwelt schlecht abbaubar und akkumulieren in Geweben exponierter Tiere, vor allem in Blut, Niere und Leber sehr stark [92]. Bei Regenbogenforellen wurden Biokonzentrationsfaktoren bis zu 25000 nachgewiesen [92]. Generell akkumulieren die Sulfonate stärker als die Carboxylate, langkettige PFTs stärker als kurzkettige.

Als Wirkmechanismus ist bekannt, dass perfluorierte Tenside mit Hormonen um Bindungsstellen an Serumproteinen, v.a. Albumin, konkurrieren und dadurch den Hormonhaushalt negativ beeinflussen [93]. Zielvorgaben für PFOA und PFOS sind weder aus der WRRL zu entnehmen noch auf EU-Ebene vorhanden. Auf EUEbene werden PFOS allerdings als "Stoffe, die einer Überprüfung zur möglichen Einstufung als „prioritäre Stoffe" oder "prioritär gefährliche Stoffe“ zu unterziehen sind“, gelistet [15]. Dies legt nahe, dass mit der Formulierung einer Zielvorgabe in naher Zukunft zu rechnen ist. Für PFOS liegt ein „risk assessment report" von 2004 vor [45].

Die Messwerte aus Argen und Schussen liegen mit maximal $0,002 \mu \mathrm{g} / \mathrm{L}-0,004 \mu \mathrm{g} / \mathrm{L}$ für PFOS und $0,001 \mu \mathrm{g} / \mathrm{L}$ - $0,01 \mu \mathrm{g} / \mathrm{L}$ für PFOA weit unter formulierten Richtwerten [44].

Aufgrund ihrer Persistenz in der Umwelt und Toxizität sowie Bioakkumulierbarkeit in aquatischen Organismen werden PFOS den so genannten PBT-Stoffen (Persistenz, Bioakkumulation, Toxizität) zugeordnet, für die sich die EU auf gemeinsame Regelungskriterien verständigt hat, und für welche nach REACH ein EU-weites Zulassungsverfahren vorgesehen ist [94]. Dies hat zur Folge, dass jede Verwendung zu beantragen ist, und dass eine
Zulassung nur erfolgt, falls keine Alternativen existieren und die sozioökonomischen Vorteile eindeutig nachgewiesen sind.

Weil PFOS zu den PBT-Stoffen gehören, verbietet die EU das Inverkehrbringen und die Verwendung dieser Stoffe seit dem 27. Juni 2008. Von dem Verbot ausgenommen sind die Anwendungen als Antireflektionsbeschichtungen für fotolithografische Verfahren und fotografische Beschichtungen bei der Herstellung von Prozessoren, für die es in der Halbleiterindustrie keine Alternative gibt. Auch ihre Verwendungen als Antischleiermittel bei Verchromungen und sonstigen galvanotechnischen Anwendungen sowie als Hydraulikflüssigkeit (Luftfahrt) sind von dem Verbot ausgenommen. Für Bestände PFOS-haltiger Feuerlöschmittel gilt eine Aufbrauchfrist von 54 Monaten.

Ökotoxikologische Wirkdaten liegen für ausgewählte invertebrate Tiergruppen [95] und Fische [96], [97] vor. Sie machen deutlich, dass bei verschiedenen Fischarten, die gegenüber PFOS bzw. PFOA exponiert wurden, zwischen $10 \mu \mathrm{g} / \mathrm{L}$ und $1 \mathrm{mg} / \mathrm{L}$ Veränderungen im Verhalten und Stoffwechsel sowie eine Beeinflussung der Expression von Genen, die in der Reproduktion und in der allgemeinen Stressantwort involviert sind, auftreten. Zudem wurden histopathologische Schäden in der Schilddrüse nach Exposition gegenüber $10 \mu \mathrm{g} / \mathrm{L}$ PFOS nachgewiesen. Endokrine Wirkungen von PFOS und PFOC wurden anhand von Experimenten mit Fischkulturzellen beschrieben [97]. Untersuchungen an Chironomiden erbrachten eine Beeinträchtigung des Wachstums nach Exposition gegenüber 27,4 $\mu \mathrm{g} / \mathrm{L}$ [95].

Auch vor dem Hintergrund dieser Daten ist bei Konzentrationen, die in den beiden Gewässern nachgewiesen wurden, nicht mit einer negativen Beeinträchtigung der Organismen zu rechnen.

\section{Flammschutzmittel (Trialkyl- Triarylphosphate,} polybromierte Diphenylether, Tetrabrombisphenol A)

Seit 1998 stehen die polybromierten Diphenylether als Stoffklasse vor allem aufgrund ihrer Persistenz und Akkumulierbarkeit in der Umwelt auf der OSPAR-Liste (Oslo/Paris-List of Substances of Possible Concern) als prioritäre Stoffe. In einer Richtlinie des Europäischen Parlamentes und Rates zur 24. Änderung der Richtlinie 76/769/EWG wurde am 18.12.2002 ein vollständiges Anwendungsverbot für PentaBDE und OctaBDE innerhalb der EU beschlossen. Pentabromdiphenylether gehören zur Liste „prioritärer Stoffe im Bereich der Wasserpolitik" nach Anhang X der Richtlinie 2000/60/ EG und wurden von der EU als prioritär gefährliche Stoffe eingestuft [15].

Untersuchungen von Wasserproben der Seefelder Aach (mündungsnah) auf 8 Flammschutzmittel (Tributylphosphat TBP, Tris[2-chlorethyl]phosphat TCEP, 
Tris(monochlorpropyl)phosphat TCPP, Tris(1,3-dichlor2-propyl)phosphat TDCP, Triphenylphosphat TPP, Tributoxyethylphosphat TBEP, Tris-(2-ethylhexyl)phosphat TEHP, Tricresylphosphat TCP) erbrachten, dass die Konzentrationen aller acht Substanzen unterhalb der Nachweisgrenze lagen [13]. In einer weiteren Studie wurden in der Seefelder Aach mündungsnah am Pegel bei Oberuhldingen $0,000034 \mu \mathrm{g} / \mathrm{L}(=34 \mathrm{pg} / \mathrm{L})$ polybromierte Diethylether (PBDE), im Ablauf der Kläranlage Grasbeuren 0,001 $\mu \mathrm{g} / \mathrm{L}$ und im Ablauf der Kläranlage Frickingen $0,00029 \mu \mathrm{g} / \mathrm{L} \quad(=290 \quad \mathrm{pg} / \mathrm{L}) \quad$ PBDE nachgewiesen. Tetrabrombisphenol A (TBBPA) war in der Seefelder Aach nicht, im Kläranlagenablauf Grasbeuren mit $0,00082 \mu \mathrm{g} / \mathrm{L}(=820 \mathrm{pg} / \mathrm{L})$, im Ablauf der Kläranlage Frickingen mit $0,00062 \mu \mathrm{g} / \mathrm{L}(=620 \mathrm{pg} / \mathrm{L})$ nachzuweisen [14].

Der Vergleich der Messwerte mit vorhandenen Grenzwerten und berechneten Zielvorgaben macht deutlich, dass die in der Seefelder Aach gemessenen Konzentrationen von Flammschutzmitteln entsprechend dieser Zielvorgabe nicht von Relevanz für die aquatische Lebewelt sein sollte. Dennoch ist aufgrund der starken Bioakkumulierbarkeit von PBDE z.B. in Fischen [98] die mögliche hormonelle Wirkung bei terrestrischen und aquatischen Organismen auch in sehr geringen Konzentrationen nicht auszuschließen. PBDE senken Gehalte an Schilddrüsenhormonen im Blut exponierter Organismen und führen zu histologischen Veränderungen der Schilddrüsenfollikel [99]. Zudem beeinflussen sie den Vitaminstoffwechsel negativ [100] und wirken immunsuppressiv [101]. In vitro-Studien, die die Ah- und Östrogenrezeptorvermittelte Expression verschiedener Gene untersuchten, zeigten ein generelles endokrines Potential von PBDE, das allerdings um den Faktor 200000 unter dem endokrinen Potential von Dioxinen liegt [102]. Ebenfalls in vitro konnten für zwei Vertreter der PBDes (BDE-99 und BDE-100) antagonistische Wirkung am Ecdysonrezeptor nachgewiesen werden, was endokrine Wirkungen bei einigen invertebraten Tiergruppen vermuten lässt [103].

\section{Bewertung der Messdaten}

Die für möglichst viele Vertreter der sieben Substanzklassen ermittelten ökotoxikologischen Wirkdaten (NOEC, LOEC, $\mathrm{EC}_{50}$ ) sind in Tab. 5, 6, 7, 8, 9, 10 und 11 zusammengestellt. Die auf den niedrigsten Effektkonzentrationen basierenden Zielvorgaben für diese Substanzen werden in Tab. 12 zusammengefasst und formulierten Qualitätsnormen gegenübergestellt.

Als in mindestens einem der drei Gewässer ökotoxikologisch relevant ergaben sich 35 Substanzen, die drei Relevanzklassen zugeordnet werden. Die ökotoxikologische Relevanz der Schadstoffe wurde in niedrig (Max. > 1/3 der oder gleich ZV), mittel (Max. < Faktor 3 über ZV) und hoch (Max. $\geq$ Faktor 3 über ZV) eingeteilt. Damit ergibt sich für die drei Flüsse folgende Gesamtbewertung:

Argen: 5 Stoffe von Relevanz

- mittlere Relevanz: Fenitrothion, Kupfer

- niedrige Relevanz: Malathion, Bromdichlormethan, Nickel

Schussen: 31 Stoffe von Relevanz

- hohe Relevanz: Diuron, Clarithromycin, Erythromycin, 17-ß-Östradiol, Östron, EE $E_{2}$ ß-Sitosterol, Bisphenol A, 4-Nonylphenol, 4-Nonylphenoxyessigsäure, 4-Octylphenol, EDTA, DTPA, KPDA, Kupfer

- mittlere Relevanz: Mecoprop, Diclofenac, Carbamazepin, Chloramphenicol, Sulfamethoxazol, 4-Nonylphenol-diethoxylat, Zink

- niedrige Relevanz: 2,4-DP, MCPA, Propiconazol, Atrazin, Simazin, Terbutryn, Bromdichlormethan, Cadmium, Nickel

Seefelder Aach: 17 Stoffe von Relevanz

- hohe Relevanz: Diuron, Bisphenol A, 4-Nonylphenol, Kupfer

- mittlere Relevanz: 2,4-DP, MCPA, Propiconazol, 17-ß-Östradiol

- niedrige Relevanz: Isoproturon, Pirimicarb, Atrazin, Terbutryn, Diclofenac, Carbamazepin, ß-Sitosterol, 4-Octylphenol, Nickel

\section{Fazit und Ausblick}

Insgesamt konnten durch die Literaturstudie für die drei Testgewässer aus fünf der sieben betrachteten Substanzklassen relevante Chemikalien identifiziert werden.

Für die Argen sind dies 5, für die Schussen 31 und für die Seefelder Aach 17 relevante Stoffe. Trotz der geringen Konzentrationen, in denen polyfluorierte Tenside und polybromierte Flammschutzmittel in den drei Testgewässern vorkommen, sollten diese beiden Substanzgruppen aufgrund ihrer Persistenz in der Umwelt und möglichen hormonellen Wirkungen, die durch sehr geringe Konzentrationen ausgelöst werden und ggf. erst in Folgegenerationen von Relevanz sein können, in künftigen Studien nicht außer acht gelassen werden. Für beide Substanzgruppen fehlen bislang ausführliche Daten zu möglichen endokrinen Effekten bei einheimischen Organismen fast völlig.

Generell sollte auch der Bedeutung der möglichen Mischungstoxizität der einzelnen Substanzen Beachtung geschenkt werden. Über Wechselwirkungen verschiedener Substanzgruppen miteinander ist bislang sehr wenig bekannt, und Modelle berücksichtigen fast ausschließlich die Wechselwirkung von Substanzen mit gleichen Wirkmechanismen. Hierbei wird bei gleichem Wirkmechanismus Wirkungsadditivität angenommen. Es ist allerdings bekannt, dass auch geringe, allein nicht wirksame Konzentrationen von Einzelsubstanzen in Kombination zu einer deutlichen Toxizität führen, und 
Tab. 5. NOECs, LOECs und /oder EC 50 -Werte aus ökotoxikologischen Untersuchungen für Pestizide

\begin{tabular}{|c|c|c|c|c|c|}
\hline PSM Referenz & Spezies & Endpunkt & $\operatorname{NOEC}(\mu \mathrm{g} / \mathrm{L})$ & LOEC $(\mu \mathrm{g} / \mathrm{L})$ & $E C_{50}(\mu \mathrm{g} / \mathrm{L})$ \\
\hline \multicolumn{6}{|l|}{ Atrazin } \\
\hline Davies et al. [106] & Oncorhynchus mykiss & Plasma-Protein & & 3 & \\
\hline Saglio \& Trijasse [107] & Carassius auratus & Verhalten & & 0,5 & \\
\hline Bringolf et al. [108] & Pimephales promelas & Reproduktion & 5 & & \\
\hline Forget-Leray et al. [109] & Eurytemora affinis (Copepoda) & life-cycle & 25 & & \\
\hline Chang et al. [110] & Cyprinus carpio & Genexpression (CY P4501A1) & & 7 & \\
\hline Tierney et al. [111] & Oncorhynchus mykiss & Verhalten & & 1 & \\
\hline Suzawa \& Ingraham [112] & Danio rerio & Genexpression (zcyp19a1) & & 2,2 & \\
\hline \multicolumn{6}{|l|}{ DEA (Desethylatrazin) } \\
\hline Belfroid et al. [113] & Anabaena "ariabilis & Photosynthese & & & 700 \\
\hline \multicolumn{6}{|l|}{ 2,4-DP (Dichlorprop) } \\
\hline Takiguchi et al. [114] & Paramecium caudatum & Motilität & & 235000 & \\
\hline Enrich-Prast [115] & Bakterien (Sediment) & Nitrifikation & 1 & 3 & \\
\hline \multicolumn{6}{|l|}{ Diuron } \\
\hline Saglio \& Trijasse [107] & Carassius auratus & Verhalten & & 5 & \\
\hline Nebeker \& Schuytema [116] & Pimephales promelas & Wachstum & & 3,4 & \\
\hline Bretaud et al. [117] & Carassius auratus & AChE-Aktivität & & 5 & \\
\hline \multicolumn{6}{|l|}{ Fenitrothion } \\
\hline Morgan \& Kiceniuk [1 18] & Salmo salar & Verhalten & & 0,04 & \\
\hline De Peyster \& Long [119] & Pimephales promelas & Verhalten & & 2,46 & \\
\hline Berrill et al. [120] & div. Amphibien & Entwicklung, Verhalten & & 2 & \\
\hline Choi et al. [121] & Chironomus riparius & Enzymaktivität (SOD) & & 0,002 & \\
\hline \multicolumn{6}{|l|}{ Isoproturon } \\
\hline Traunspurger et al [122] & $\begin{array}{l}\text { Chlamydomonas reinhardi } \\
\text { cenedesmus subspicatus } \\
\text { Tetrahymena pyriformis } \\
\text { Daphnia magna } \\
\text { Caenorhabditis elegans }\end{array}$ & $\begin{array}{l}\text { Wachstumsrate } \\
\text { Wachstumsrate } \\
\text { Wachstumsrate } \\
\text { Immobilisation } \\
\text { Wachstum (Länge) }\end{array}$ & & & $\begin{aligned} & 40 \\
& 12-15 \\
&> 1100 \\
&> 1000 \\
&> 810\end{aligned}$ \\
\hline Greulich et al. [123] & Bombina bombina, Bombina variegata & Larvalentwick-lung, Stoffwechsel & & 0.1 & \\
\hline Hurst \& Sheahan [124] & Saccharomyces cerevisiae & $\begin{array}{l}\text { Hefezell-Östrogentest } \\
\text { (Routledge \& Sumpter 1996) }\end{array}$ & & 1560 & \\
\hline Schmitt-Jansen \& Altenburger [125] & Periphyton & Photosynthese-Hemmung & & & 40 \\
\hline Küster \& Altenburger [126] & $\begin{array}{l}\text { Lemna minor } \\
\text { Chara canescens }\end{array}$ & Fluoreszenz (Chl a, PSII) & & & $\begin{array}{l}33,8 \\
78,8\end{array}$ \\
\hline Vallotton et al. [127] & Scenedesmus vacuolatus & Wachstum & & & 136 \\
\hline Dewez et al. [128] & Scenedesmus obliquus & $\begin{array}{l}\text { - Zellteilung (Dichte) } \\
\text { - Fluoreszenz (Chl a, PSII) }\end{array}$ & & & $\begin{array}{c}103 \\
8-165\end{array}$ \\
\hline \multicolumn{6}{|l|}{ Malathion } \\
\hline Desi et al [129] & Flussmuschel (Larven, Glochidien) & Schalenschluss & & 1 & \\
\hline Cook et al. [130] & Danio rerio & Entwicklung & & 2000 & \\
\hline Ren et al [131] & Daphnia magna & Schwimmverhalten & & & 0,9 \\
\hline \multicolumn{6}{|l|}{ Mecoprop } \\
\hline EU [132] & $\begin{array}{l}\text { Fisch } \\
\text { Wirbellose } \\
\text { Wirbellose }\end{array}$ & $\begin{array}{l}\text { Toxizität } \\
\text { Toxizität } \\
\text { Reproduktion }\end{array}$ & 109000 & & $\begin{array}{l}>200000 \\
>22000\end{array}$ \\
\hline \multicolumn{6}{|l|}{ MCPA } \\
\hline Hattula et al. [133] & $\begin{array}{l}\text { Salmo trutta } \\
\text { Carassius auratus }\end{array}$ & $\begin{array}{l}\text { Histopathologie } \\
\text { Leber, Niere, Kieme }\end{array}$ & $\begin{array}{l}30000 \\
60000\end{array}$ & & \\
\hline Woin \& Brönmark [134] & Lymnaea stagnalis & Ei-Produktion & & $6308(10000)$ & \\
\hline Davies et al. [106] & Oncorhynchus mykiss & Blutparameter & & 50000 & \\
\hline Johansson et al. [135] & Rana temporaria & Larvalentwicklung & 12000 & & \\
\hline \multicolumn{6}{|l|}{ Pirimicarb } \\
\hline Honrubia et al. [136] & Rana perezi & Mortalität, Histologie Leber, Kieme etc. & & 20000 & \\
\hline Widenfalk et al. [137] & Mikroorganismen (Sediment) & Bakterielle Aktivität & & 0,09 & \\
\hline Johansson et al. [135] & Rana temporaria & Larvalentwicklung & 416000 & & \\
\hline
\end{tabular}


Tab. 5. Continued

\begin{tabular}{|c|c|c|c|c|c|}
\hline PSM Referenz & Spezies & Endpunkt & $\operatorname{NOEC}(\mu \mathrm{g} / \mathrm{L})$ & $\operatorname{LOEC}(\mu \mathrm{g} / \mathrm{L})$ & $\mathrm{EC}_{50}(\mu \mathrm{g} / \mathrm{L})$ \\
\hline \multicolumn{6}{|l|}{ Propiconazol } \\
\hline Levine et al. [138] & Oncorhynchus mykiss & Leber: CYP1A-Expression & & 19 & \\
\hline Kast-Hutcheson et al. [139] & Daphnia magna & Entwicklung & & 250 & \\
\hline Hurst \& Sheahan [124] & Saccharomyces cerevisiae & $\begin{array}{l}\text { Hefezell-Östrogentest } \\
\text { (Routledge \& Sumpter 1996) }\end{array}$ & & 12500 & \\
\hline Wu et al. [140] & Vesicularia dubyana (Javamoos) & Photosyntheserate & & 1 & \\
\hline Bringolf et al. [141] & Lampsilis siliquoidea & $\begin{array}{l}\text { Glochidien-Tox. } \\
\text { Juvenil-Tox. }\end{array}$ & & & $\begin{array}{l}19210(48 h) \\
10010(96 h)\end{array}$ \\
\hline \multicolumn{6}{|l|}{ Simazin } \\
\hline Wilson et al. [142] & Cannahybrida & Photosynthese & & 1000 & \\
\hline Dodson \& Mayfield [143] & Oncorhynchus mykiss & Verhalten & & 1000 & \\
\hline Arufe et al. [144] & Sparus aurata & Verhalten & & 4500 & \\
\hline Moore \& Lower [145] & Salmo salar & Testosteron & & 0,13 & \\
\hline \multicolumn{6}{|l|}{ Terbutryn } \\
\hline Brust et al. [146] & $\begin{array}{l}\text { Aufwuchs (Ulothrix sp., Cladophora sp., } \\
\text { Achnanthes sp., Nitzschia sp) } \\
\text { Populationswachstum Lumbriculus } \\
\text { variegatus }\end{array}$ & Wachstum & & $\begin{array}{c}0,6 \\
6\end{array}$ & \\
\hline Rioboo et al. [147] & Brachionus sp. & Reproduktion, Wachstum & & 24 & \\
\hline
\end{tabular}

Tab. 6. NOECs, LOECs und /oder $\mathrm{EC}_{50}$-Werte aus ökotoxikologischen Untersuchungen für Arzneimittel, Phytoöstrogene und Insektenschutzmittel

\begin{tabular}{|c|c|c|c|c|c|}
\hline Arzneimittel Referenz & Spezies & Endpunkt & NOEC ( $\mu \mathrm{g} / \mathrm{L})$ & $\operatorname{LOEC}(\mu \mathrm{g} / \mathrm{L})$ & $E C_{50}(\mu \mathrm{g} / \mathrm{L})$ \\
\hline \multicolumn{6}{|l|}{ Carbamazepin } \\
\hline Pfluger et al. [148] & Daphnia magna & Bewegung & & & 74000 \\
\hline Pfluger et al. [148] & Xenopus laevis & Teratogenität & & & 103000 \\
\hline Pfluger et al. [148] & Danio rerio & Teratogenität & & & 84000 \\
\hline Ferrari et al. [149] & Ceriodaphnia dubia & Mobilität & 25 & 100 & \\
\hline Schwaiger \& Negele [150] & Cyprinus carpio & & & 1 & \\
\hline Liebig [151] & Danio rerio & Embryotoxizität & & & $<100000$ \\
\hline Liebig [151] & Daphnia magna & Reproduktion, Wachstum & 400 & 1260 & \\
\hline Triebskorn et al. [75] & Cyprinus carpio & Ultrastruktur der Niere & & 1 & \\
\hline \multicolumn{6}{|l|}{ Chloramphenicol } \\
\hline Lai et al. [152] & Chlorella pyrenoidosa & Wachstum & & & 14000 \\
\hline \multicolumn{6}{|l|}{ Clarithromycin } \\
\hline Isidori et al. [153] & Pseudokirchneriella subcapitata & Wachstum & & & 2 \\
\hline Isidori et al. [153] & Cerodaphnia. dubia & Mobilität & & & 8160 \\
\hline \multicolumn{6}{|l|}{ Diclofenac } \\
\hline Cleuvers [68] & Lemna gibba & Wachstum & & & 7500 \\
\hline Ferrari et al. [149] & Danio rerio & Mortalität & & 8000 & \\
\hline Schwaiger et al. [154] & Oncorhynchus mykiss & Histopathologie & & 5 & \\
\hline Triebskorn et al. [75] & Oncorhynchus mykiss & Ultrastruktur von Leber, Kieme, Niere & & 1 & \\
\hline Isidori et al. [153] & Pseudokirchneriella subcapitata & Wachstum & & & 20 \\
\hline Isidori et al. [153] & Cerodaphnia. dubia & Wachstum & & & 220 \\
\hline Isidori et al. [153] & Danio rerio & Mortalität & 1000000 & & \\
\hline \multicolumn{6}{|l|}{ Diethyltoluolamid (DEET) } \\
\hline Xue et al. [155] & $\begin{array}{l}\text { Cypricercus sp. (Ostracoda), Moina sp. } \\
\text { (Cladocera), Eucyclops agilis (Copepoda), } \\
\text { Strelkovimermis spiculatus (Nematoda), } \\
\text { Toxorhynchite Larve (Diptera), } \\
\text { Chironomus decorus (Diptera) }\end{array}$ & & & & $\begin{array}{c}\mathrm{LC}_{50} \\
120000- \\
1270000\end{array}$ \\
\hline
\end{tabular}


Tab. 6. Continued

\begin{tabular}{|c|c|c|c|c|c|}
\hline Arzneimittel Referenz & Spezies & Endpunkt & NOEC ( $\mu \mathrm{g} / \mathrm{L})$ & $\operatorname{LOEC}(\mu \mathrm{g} / \mathrm{L})$ & $\mathrm{EC}_{50}(\mu \mathrm{g} / \mathrm{L})$ \\
\hline \multicolumn{6}{|l|}{ 17a-Ethinylestradiol $\mathrm{EE}_{2}$} \\
\hline Purdom et al [156] & $\begin{array}{l}\text { Cyprinus carpio } \\
\text { Oncorhynchus mykiss (Männchen) }\end{array}$ & $\begin{array}{l}\text { Vitellogenin } \\
\text { Vitellogenin }\end{array}$ & & $\begin{array}{c}0,010 \\
0,0001\end{array}$ & \\
\hline Wenzel et al. [157] & Danio rerio & Befruchtung & & 0,0011 & \\
\hline Länge et al. [158] & Pimephales promelas & Full life-cycle & 0,001 & 0,004 & \\
\hline Panter et al. [159] & Pimephales promelas & Vitellogenin & & 0,002 & \\
\hline Watts et al. [160] & Gammarus pulex & $\begin{array}{l}\text { Geschlechterverhältnis } \\
\text { Populationsgröße }\end{array}$ & & $\begin{array}{c}0,1 \\
1\end{array}$ & \\
\hline Jobling et al. [161] & $\begin{array}{l}\text { Potamopyrgus antipodarum } \\
\text { Pimephales promelas }\end{array}$ & Eiproduktion & & $\begin{array}{c}0,001 \\
0,0001\end{array}$ & \\
\hline Segner et al. [162] & Danio rerio & Vitellogenin & & 0,0017 & \\
\hline Segner et al. [162] & Hydra vulgaris & Spermienaktivität & & 500 & \\
\hline Segner et al. [162] & Gammarus pulex & Populationsstruktur & & 1 & \\
\hline Segner et al. [162] & Chironomus riparius & Mundwerkzeuge & & 10 & \\
\hline Thomas-Jones et al. [163] & Oncorhynchus mykiss & $\begin{array}{l}\text { Vitellogenin mRNA } \\
\text { VEPa (Leber) }\end{array}$ & & $\begin{array}{l}0,001 \\
0,001\end{array}$ & \\
\hline Weber et al. [164] & Oryzias latipes & Zelltod (Leber, Niere) & & 0,01 & \\
\hline Nash et al [165] & Danio rerio & Reproduktion (F1) & & & 0,005 \\
\hline Parrott \& Blunt [166] & Pimephales promelas & Reproduktion & & 0,00032 & \\
\hline \multicolumn{6}{|l|}{ Genistein } \\
\hline Panter et al [159] & Pimephales promelas & Vitellogenin & & 0,07 & \\
\hline Kiparissis et al [167] & Oryzias latipes & Gonaden-Intersex & & 1000 & \\
\hline Ingham et al. [168] & $\begin{array}{l}\text { Pimephales promelas } \\
\text { Xenopus laevis }\end{array}$ & $\begin{array}{l}\text { Wachstum, Überlebensrate, } \\
\text { Asymmetrie Entwicklung }\end{array}$ & 1280 & 80 & \\
\hline \multicolumn{6}{|l|}{ 17-ß-Östradiol } \\
\hline Thomas-Jones et al. [163] & Oncorhynchus mykiss & $\begin{array}{l}\text { Vitellogenin-mRNA } \\
\text { (Leber) }\end{array}$ & & $\begin{array}{c}0,014 \\
0,0048\end{array}$ & \\
\hline Seki et al. [169] & Oryzias latipes & Reproduktion & 0,00286 & 0,00866 & \\
\hline Filby et al. [170] & Pimephales promelas & Genexpression & & 0,032 & \\
\hline Seki et al. [171] & $\begin{array}{l}\text { Oryzias latipes } \\
\text { Pimephales promelas } \\
\text { Danio rerio }\end{array}$ & Vitellogenin & & $\begin{array}{l}0,00894 \\
0,0286 \\
0,0859\end{array}$ & \\
\hline Van der Ven et al. [172] & Danio rerio & Entwicklung, Reproduktion & & 0,027 & \\
\hline \multicolumn{6}{|l|}{ Östron } \\
\hline Bjerregaard et al. [173] & Salmo trutta & Vitellogenin & & & 0,088 \\
\hline \multicolumn{6}{|l|}{ B-Sitosterol } \\
\hline Trembley \& van der Kraak [70] & Oncorhynchus mykiss & Vitellogenin & & 25 & \\
\hline Lehtinen et al. [174] & Salmo trutta lacustris & Larvalentwicklung & & 10 & \\
\hline Czech et al [76] & Lymnaea stagnalis & Reproduktion (Histopathologie) & & 0,1 & \\
\hline Honkanen et al. [175] & Thymallus thymallus & $\begin{array}{l}\text { Reproduktion (Schlüpfzeit) } \\
\text { Hormonpegel (T3,T4) }\end{array}$ & 50 & 1 & \\
\hline \multicolumn{6}{|l|}{ Sulfamethoxazol } \\
\hline Brain et al. [176] & Lemna gibba & Phototoxizität & 10 & 30 & \\
\hline Liebig [151] & Lemna gibba- & Phototoxizität & & 10 & \\
\hline Liebig [151] & Scenedesmus subspicatus & Wachstum & & 2500 & \\
\hline Liebig [151] & Danio rerio & Teratogenese, Herzschlag & & & $>100000$ \\
\hline Isidori et al. [153] & Cerodaphnia dubia & Mobilität & & & 210 \\
\hline \multicolumn{6}{|l|}{ Trimethoprim } \\
\hline Kolpin et al. [177] & Oncorhynchus mykiss & Mortalität & & & $\mathrm{LC}_{50} 3000$ \\
\hline
\end{tabular}




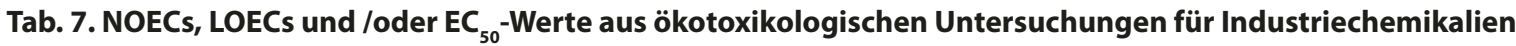

\begin{tabular}{|c|c|c|c|c|c|}
\hline Industriechemikalien Referenz & Spezies & Endpunkt & NOEC $(\mu \mathrm{g} / \mathrm{L})$ & $\operatorname{LOEC}(\mu \mathrm{g} / \mathrm{L})$ & $\mathrm{EC}_{50}(\mu \mathrm{g} / \mathrm{L})$ \\
\hline \multicolumn{6}{|l|}{ BPA } \\
\hline Oehlmann, et al. [178] & Marisa cornuarietis & Super-Weibchen (endokrine Wirkung) & & 1 & \\
\hline Sohoni et al. [179] & Pimephales promelas & Schlupfrate & 16 & & \\
\hline Hahn et al. [180] & Chironomus riparius & Vitellogenin & & 1 & \\
\hline Pascoe et al. [181] & Hydra vulgaris & Polypenhabitus & 42 & & \\
\hline Segner et al. [162] & Danio rerio & Vitellogenin & & 375 & \\
\hline Segner et al. [162] & Hydra vulgaris & Regeneration & & 1 & \\
\hline Segner et al. [162] & Gammarus pulex & Paarbildung & & 830 & \\
\hline Segner et al. [162] & Chironomus riparius & Häutung & & 1000 & \\
\hline Van der Hoeven[182] & Marisa cornuarietis & Eiablage & & & 2,1 (EC10) \\
\hline Oehlmann et al. [183] & $\begin{array}{l}\text { Marisa cornuarietis } \\
\text { Nucella lapillus }\end{array}$ & Super-Weibchen (endokrine Wirkung) & 0,0079 & & $0,0139\left(\mathrm{EC}_{10}\right)$ \\
\hline Forbes et al. [184] & Marisa cornuarietis & $\begin{array}{l}\text { Reproduktion } \\
\text { Wachstum Weibchen } \\
\text { Wachstum Männchen }\end{array}$ & 640 & $\begin{array}{c}640 \\
1\end{array}$ & \\
\hline \multicolumn{6}{|l|}{ Bromdichlormethan } \\
\hline Toussaint et al. [185] & Oryzias latipes & Histopathologie (Leber) & & 1424 & \\
\hline \multicolumn{6}{|l|}{ Nonylphenol } \\
\hline Schwaiger et al. [186] & Cyprinus carpio & $\begin{array}{l}\text { Blutparameter } \\
\text { Histopathologie Leber, Niere }\end{array}$ & $\begin{array}{l}1-5 \\
15\end{array}$ & $5-10$ & \\
\hline Hahn et al. [180] & Chironomus riparius & Dotterprotein & & 1,9 & \\
\hline Schwaiger et al. [187] & Oncorhynchus mykiss & $\begin{array}{l}\text { Vitellogenin } \\
\text { Schlupfrate }\end{array}$ & & $\begin{array}{c}1 \\
10\end{array}$ & \\
\hline Seki et al. [188] & Oryzias latipes & $\begin{array}{l}\text { Geschlechtsdifferenzierung } \\
\text { Vitellogenin }\end{array}$ & & 11,6 & \\
\hline Lahnsteiner et al. [189] & Oncorhynchus mykiss & $\begin{array}{l}\text { Spermatogenese } \\
\text { Ei-Entwicklung }\end{array}$ & & $\begin{array}{l}0,13 \\
0,28\end{array}$ & \\
\hline Lee \& Choi [190] & Chironomus riparius & $\begin{array}{l}\text { div. Biomarker } \\
\text { (Stressproteine, DNA-Schäden) }\end{array}$ & & 1 & \\
\hline Schubert et al. [191] & Salmo trutta & Vitellogenin & & 0,111 & \\
\hline \multicolumn{6}{|l|}{ Octylphenol } \\
\hline Jobling et al. [192] & Oncorhynchus mykiss & Vitellogenin & & 4,8 & \\
\hline Oehlmann et al. [178] & Marisa cornuarietis Nucella lapillus & $\begin{array}{l}\text { Super-Weibchen } \\
\text { (endokrine Wirkung) }\end{array}$ & & 1 & \\
\hline Andersen et al. [193] & Acartia tonsa (Copepoda) & Larvalentwicklung & & & 13 \\
\hline Seki et al. [188] & Oryzias latipes & $\begin{array}{l}\text { Geschlechtsdifferenzierung } \\
\text { Vitellogenin }\end{array}$ & & 11,4 & \\
\hline Karels et al. [194] & Cyprinodon variegatus & Vitellogenin & & 11,5 & \\
\hline Bjerregaard et al. [173] & Salmo trutta & Vitellogenin & & & 7 \\
\hline
\end{tabular}

Tab. 8. NOECs, LOECs und /oder $\mathrm{EC}_{50}$-Werte aus ökotoxikologischen Untersuchungen für Komplexbildner

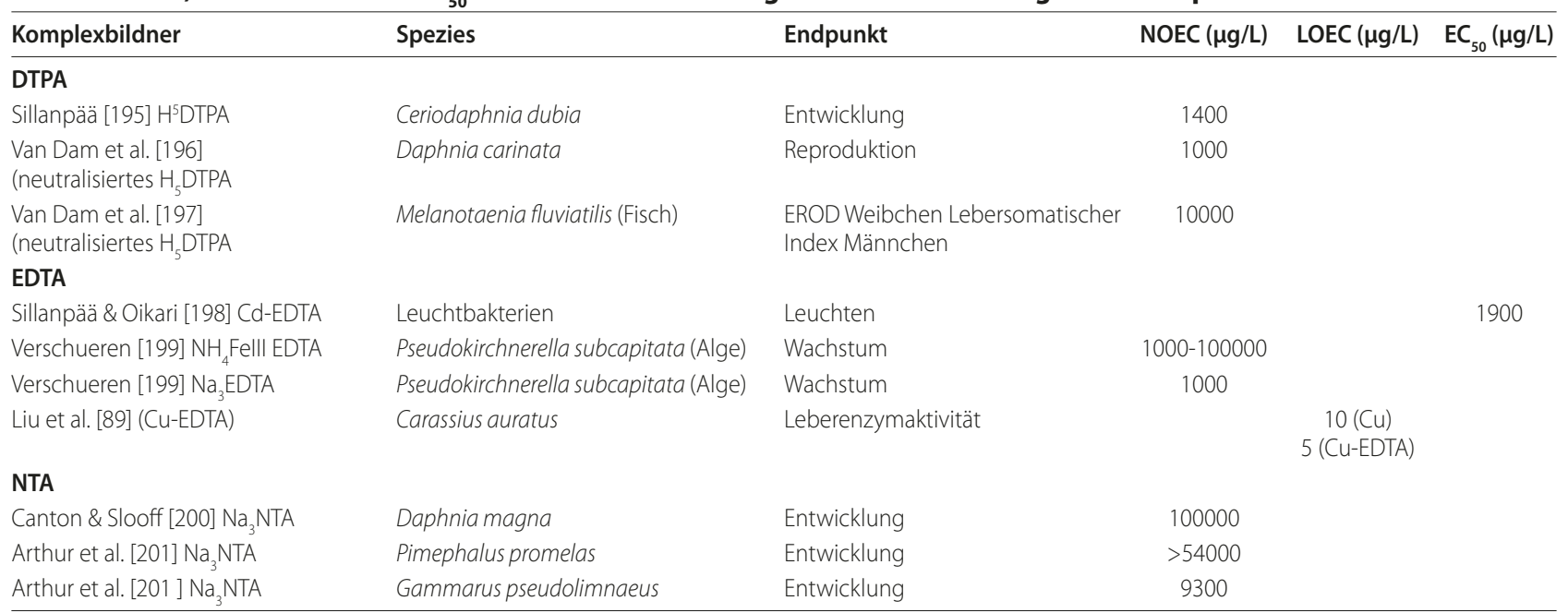


Tab. 9. NOECs, LOECs und /oder EC ${ }_{50}$-Werte aus ökotoxikologischen Untersuchungen für Nickel, Cadmium, Zink und Kupfer

\begin{tabular}{|c|c|c|c|c|c|}
\hline Metalle & Spezies & Endpunkt & NOEC $(\mu \mathrm{g} / \mathrm{L})$ & LOEC ( $\mu \mathrm{g} / \mathrm{L})$ & $\mathrm{EC}_{50}(\mu \mathrm{g} / \mathrm{L})$ \\
\hline \multicolumn{6}{|l|}{ Cadmium } \\
\hline Sellin et al. [202] & Pimephales promelas & Reproduktion & & 12,5 & \\
\hline Kusch et al. [203] & Danio rerio & $\begin{array}{l}\text { Verhalten } \\
\text { Entwicklung (Mortalität) }\end{array}$ & & $\begin{array}{l}20 \\
0,2\end{array}$ & \\
\hline Besser et al. [204] & $\begin{array}{l}\text { Cottus bairdi } \\
\text { Oncorhynchus mykiss }\end{array}$ & $\begin{array}{l}\text { ELS (Mortalität, 14d) } \\
\text { ELS (Mortalität, 28d) }\end{array}$ & $\begin{array}{l}0,59 \\
1,3\end{array}$ & $\begin{array}{l}1,3 \\
2,7\end{array}$ & $\begin{array}{l}1,73 \\
5,5\end{array}$ \\
\hline Brinkman \& Hansen [205] & Salmo trutta & ELS & 4,87 & 4,87 & \\
\hline Gross et al. [206] & Rana pipiens & Embryo-Mortalität, Entwicklung & & 5 & \\
\hline Asagba et al. [207] & Clarias gariepinus & Biochemie Leber, Niere, Kieme (SOD) & & 0,2 & \\
\hline \multicolumn{6}{|l|}{ Kupfer } \\
\hline Nebeker et al. [208] & Clistoronia magnifica & Entwicklung & 8,3 & 13 & \\
\hline Dave \& Xiu [209] & Danio rerio & Schlupf & 0,05 & & \\
\hline Liu et al. [89] & Carassius auratus & Leberenzymaktivität & & $\begin{array}{c}10(\mathrm{Cu}) \\
5(\mathrm{Cu}-\mathrm{EDTA})\end{array}$ & \\
\hline Besser et al. [204] & $\begin{array}{l}\text { Cottus bairdi } \\
\text { Oncorhynchus mykiss }\end{array}$ & $\begin{array}{l}\text { ELS (Mortalität, 21d) } \\
\text { ELS (Mortalität, 28d) }\end{array}$ & $\begin{array}{l}2,9 \\
27\end{array}$ & $\begin{array}{l}6,7 \\
59\end{array}$ & $\begin{array}{l}4,5 \\
56\end{array}$ \\
\hline Craig et al. [210] & Danio rerio & Genexpression (COX-17) & & 8 & \\
\hline Moreira-Santos et al. [211] & Danio rerio & Verhalten (Vermeidung) & & & $16-23$ \\
\hline Kamunde et al. [212] & Oncorhynchus mykiss & Plasma Vitamin E & & 40 & \\
\hline Knakievicz \& Ferreira [213] & Girardia tigrina (Planarie) & Reproduktion & & 50 & \\
\hline \multicolumn{6}{|l|}{ Nickel } \\
\hline Nebeker et al. [208] & Clistoronia magnifica & Entwicklung & 66 & 250 & \\
\hline Nebeker et al. [214] & Oncorhynchus mykiss Larve & Entwicklung & 35 & 134 & \\
\hline Dave \& Xiu [209] & Danio rerio & Schlupf & 40 & & \\
\hline Kienle et al. [215] & Danio rerio & Verhalten & & 7500 & \\
\hline Senatori et al. [216] & Danio rerio & Nervenenzym Monoaminoxidase (MAC & AO) & 500 & \\
\hline \multicolumn{6}{|l|}{ Zink } \\
\hline Woodling et al. [217] & Cottus bairdi & Mortalität & 16 & 27 & \\
\hline Aitt-Aïssa et al. [218] & Oncorhynchus mykiss & Biomarker Leber (GSH, SOD) & & 150 & \\
\hline Besser et al. [204] & $\begin{array}{l}\text { Cottus bairdi } \\
\text { Oncorhynchus mykiss }\end{array}$ & $\begin{array}{l}\text { ELS (Mortalität, 14d) } \\
\text { ELS (Mortalität, 28d) }\end{array}$ & $\begin{array}{l}150 \\
150\end{array}$ & $\begin{array}{l}320 \\
320\end{array}$ & $\begin{array}{l}233 \\
504\end{array}$ \\
\hline
\end{tabular}

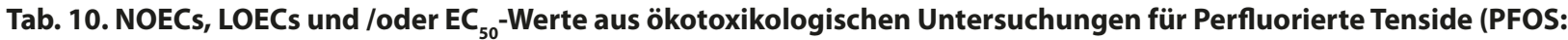
Perfluoroctansulfonat; PFOA: Perfluoroctansäure)

\begin{tabular}{|c|c|c|c|c|c|}
\hline & Spezies & Endpunkt & $\operatorname{NOEC}(\mu \mathrm{g} / \mathrm{L})$ & $\operatorname{LOEC}(\mu \mathrm{g} / \mathrm{L})$ & $\mathrm{EC}_{50}(\mu \mathrm{g} / \mathrm{L})$ \\
\hline \multicolumn{6}{|l|}{ PFOA } \\
\hline MacDonald et al. [95] & Chironomus tentans & Wachstum, Emergenz & & & $>100000$ \\
\hline Ji et al. [219] & Daphnia magna & Entwicklung & 12500 & & \\
\hline Ji et al. [219] & Oryzias latipes & Histopathologie Schilddrüse & 100 & & \\
\hline \multicolumn{6}{|l|}{ PFOS } \\
\hline Martin et al. [220] & Oncorhynchus mykiss & Verhalten & & 1000 & \\
\hline Boudreau et al. [221] & Daphnia magna & Immobilität & 5300 & & \\
\hline MacDonald et al. [95] & $\begin{array}{l}\text { Chironomus tentans } \\
\text { Chironomus tentans }\end{array}$ & $\begin{array}{l}\text { Wachstum } \\
\text { Emergenz }\end{array}$ & & & $\begin{array}{l}27,4 \\
94,5\end{array}$ \\
\hline Ji et al. [219] & Daphnia magna & Entwicklung & 1250 & & \\
\hline Ji et al. [219] & $\begin{array}{l}\text { Oryzias latipes } \\
\text { Oryzias latipes }\end{array}$ & $\begin{array}{l}\text { GSI (Gonadosomatischer Index) } \\
\text { Schlupf F1, Histopathologie Schilddrüse }\end{array}$ & $\begin{array}{l}10 \\
10\end{array}$ & & \\
\hline Hagenaars et al. [96] & Cyprinus carpio & Konditionsfaktor & & 100 & \\
\hline
\end{tabular}


Tab. 11. NOECs, LOECs und /oder $\mathrm{EC}_{50}$-Werte aus ökotoxikologischen Untersuchungen für Polybromierte Diphenylether (PBDE)

\begin{tabular}{lllc}
\hline PBDE & Spezies & Endpunkt & LOEC $(\boldsymbol{\mu g} / \mathbf{L})^{\text {EC }}(\boldsymbol{\mu g} / \mathbf{L})$ \\
\hline Villeneuve et al. [102] & Zellinien & Rezeptorbindung & $500 \mathrm{ng} / \mathrm{ml}$ \\
Breitholz \& Wollenberger [222] & Nicotra spinipes Copepoda & Entwicklung & $13($ (BDE-47) \\
Wollenberger et al. [103] & Acartia tonsa Drosophila Zelllinie & Entwicklung Rezeptorbindung & $30(\mathrm{BDE}-99)$ \\
Nakari \& Huhtala [223] & Daphnia magna & Entwicklung & 12,5 \\
Key et al. [224] & Palaemonetes pugio & Cholesterol & 6,25 \\
\hline
\end{tabular}

Tab. 12. Ableitung von Zielvorgaben für ausgewählte Mikrospurenstoffe auf der Basis von ökotoxikologischen Studien

\begin{tabular}{|c|c|c|c|c|}
\hline Wirkstoff & $\begin{array}{l}\text { Max. Konzentration } \\
\text { in einem der } \\
\text { drei Flüsse }(\mu \mathrm{g} / \mathrm{L})\end{array}$ & $\begin{array}{c}\text { Niedrigste UQN } \\
\text { [WRRL /EU (2008a, } \\
\text { Datenbanken)]( } \mu \mathrm{g} / \mathrm{L})\end{array}$ & $\begin{array}{c}\text { Niedrigste Effektkonzentration } \\
\text { aus ökotoxikologischen Studien } \\
\text { LOEC/EC }_{50}(\mu \mathrm{g} / \mathrm{L})\end{array}$ & $\begin{array}{l}\text { ZV-Vorschlag auf Basis } \\
\text { von ökotoxikologischen } \\
\text { Untersuchungen (:SF) ( } \mu \mathrm{g} / \mathrm{L})\end{array}$ \\
\hline \multicolumn{5}{|l|}{ Pestizide } \\
\hline Atrazin & 0,01 & 0,01 & 0,5 & $(: 10) 0,05$ \\
\hline DEA (Desethylatrazin) & 0,02 & & 700 & (:10) 70 \\
\hline 2,4-DP (Dichlorprop) & 0,23 & 0,1 & 1 & $(: 10) 0,1$ \\
\hline Diuron & 0,11 & 0,006 & 3,4 & $(: 10) 0,34$ \\
\hline Fenitrothion & 0,003 & 0,001 & 0,04 & $(: 10) 0,004$ \\
\hline Isoproturon & 0,06 & 0,1 & 0,1 & $(: 10) 0,01$ \\
\hline Malathion & 0,001 & 0,001 & 0,9 & (:10) 0,09 \\
\hline MCPA & 0,16 & 0,1 & 6308 & $(: 10) 631$ \\
\hline Mecoprop & 0,16 & 0,1 & 22000 & $(: 100) 220$ \\
\hline Pirimicarb & 0,08 & 0,09 & 0,09 & $(: 10) 0,009$ \\
\hline Propiconazol & 0,01 & 0,01 & 1 & $(: 10) 0,1$ \\
\hline Simazin & 0,04 & 0,06 & 0,13 & (:10) 0,01 \\
\hline Terbutryn & 0,017 & 0,03 & 0,6 & $(: 10) 0,06$ \\
\hline \multicolumn{5}{|c|}{ Arzneimittel, Östrogene, Phytoöstrogene } \\
\hline Carbamazepin & 0,27 & 0,1 & 1 & $(: 50) 0,02$ \\
\hline Clarithromycin & 0,07 & 0,002 & 2 & $(: 50) 0,04$ \\
\hline Chloramphenicol & 0,04 & 0,02 & 14000 & $(: 1000) 14$ \\
\hline Diclofenac & 0,14 & 0,1 & 1 & $(: 50) 0,1$ \\
\hline EE2 & 0,005 & 0,00003 & 0,0001 & $(: 10) 0,00001$ \\
\hline Erythromycin & 0,14 & 0,02 & 20 & $(: 50) 0,4$ \\
\hline Genistein & 0,0063 & 0,013 & 0,07 & $(: 10) 0,007$ \\
\hline 17-ß-Östradiol & 0,032 & 0,0005 & 0,004 & $(: 10) 0,0004$ \\
\hline Östron & 0,009 & 0,003 & 0,088 & $(: 10) 0,0088$ \\
\hline B-Sitosterol & 1,76 & & 0,1 & $(: 10) 0,01$ \\
\hline Sulfamethoxazol & 0,2 & 0,15 & 10 & $(: 50) 0,2$ \\
\hline Trimethoprim & 0,03 & & 3000 & $(: 1000) 3$ \\
\hline \multicolumn{5}{|l|}{ Industriechemikalien } \\
\hline Bisphenol A & 0,41 & 0,0008 & 0,0079 & $(: 10) 0,0008$ \\
\hline Bromdichlormethan & 0,06 & 0,1 & 1424 & $(: 100) 14,24$ \\
\hline Diethyltoluolamid & 0,048 & & 120000 & (:1000) 120 \\
\hline 4-Nonylphenol & 0,16 & $0,0033[0,3]$ & 0,1 & $(: 10) 0,01$ \\
\hline 4-Octylphenol & 0,098 & 0,01 & 1 & $(: 10) 0,1$ \\
\hline \multicolumn{5}{|l|}{ Komplexbildner } \\
\hline DTPA & 124 & 10 & 1000 & $100(: 10)$ \\
\hline EDTA & 33 & $10[10]$ & 1000 & $100(: 10)$ \\
\hline NTA & 1,2 & $10[50]$ & 9300 & $930(: 10)$ \\
\hline \multicolumn{5}{|l|}{ Metalle } \\
\hline Cadmium & 0,1 & $0,07[1]$ & 0,2 & 0,02 \\
\hline Kupfer & 6,6 & $4[1,6-9,3]$ & 0,05 & 0,005 \\
\hline Nickel & 4,2 & 4,4 [20] & 134 & 13,4 \\
\hline Zink & 27 & $14[9,6-29,9]$ & 27 & 2,7 \\
\hline \multicolumn{5}{|l|}{ Perfluorierte Tenside } \\
\hline PFOA & 0,01 & 1,2 & 100 & $10(: 10)$ \\
\hline PFOS & 0,004 & 1,2 & 10 & $1(: 10)$ \\
\hline \multicolumn{5}{|l|}{ Flammschutzmittel } \\
\hline PBDE & $0,000034 \mu \mathrm{g} / \mathrm{L}$ & 0,0005 (EU, 2008a) & 1,2 & 0,012 \\
\hline
\end{tabular}


Substanzen mit unterschiedlichem Wirkmechanismus interferierend agieren können. Zu solchen unabhängigen Wirkungen existieren bislang allerdings kaum Methoden zur Vorhersage der Mischungstoxizität.

Aufgrund der hohen Wahrscheinlichkeit, dass in Schussen und Seefelder Aach Mischungseffekte von großer Bedeutung sind, sollte die Abschätzung des toxischen Potentials in diesen Gewässern möglichst freilandbezogen erfolgen.

\section{Danksagungen}

Unser Dank gilt der Landesanstalt für Umwelt, Messungen und Naturschutz Baden-Württemberg, dem Ministerium für Umwelt, Klima und Energiewirtschaft Baden-Württemberg sowie der Stiftung "Natur und Umwelt" der Landesbank Baden-Württemberg für die finanzielle Unterstützung sowie Herrn Hans-Joachim Vogel, Regierungspräsidium Tübingen für die Initiierung der Studie. Frau Stefanie Krais danken wir fur die Unterstützung bei der Formatierung des Manuskripts.

Beitrag der Autoren: Die Literaturstudie wurde von Rita Triebskorn durchgeführt. Die Erstversion des Manuskripts wurde von Rita Triebskorn erarbeitet, die Endversion von beiden Autoren überarbeitet und genehmigt.

\section{Competing interests}

The authors declare that they have no competing interests.

\section{Author details}

'Physiologische Ökologie der Tiere, Universität Tübingen, KonradAdenauer- Str. 20, 72072 Tübingen, Germany. ${ }^{2}$ Steinbeis Transferzentrum für Ökotoxikologie und Ökophysiologie, Blumenstr. 13, 72108 Rottenburg, Germany. ${ }^{3}$ Institut für Seenforschung (ISF) der LUBW, Argenweg 50/1, 88085 Langenargen, Germany.

Received: 30 June 2011 Accepted: 6 February 2012 Published: 6 February 2012

\section{Literatur}

1 WRRL: Qualitätsziele für chemische Stoffe in Oberflächengewässern Arbeitskreis Chemie, Überwachung, Ziele; 2003.

2 IGKB: Jahresbericht der Internationalen Gewässerschutzkommission für den Bodensee: Limnologischer Zustand des Bodensees. Internationale Gewässerschutzkommission für den Bodensee (Hrsg.) Langenargen, 38: 19; 2010

3 Hetzenauer H, Kaiser H: Pflanzenschutzmittel in Bodenseezuflüssen. LUBW unveröffentlicht 2008.

4 LUBW: Originaldaten LUBW Karlsruhe Abt. IV: Beprobungen 2005-2007; 2008

5 Fleig M, Brauch HJ, Kühn W: Ergebnisse der AWBR-Untersuchungen im Jahr 2000. AWBR-Berichte 2000, 32:39-58

6 Krieger H, Lampsdörfer T, Dietrich DR: Status- und Strategiebericht Schadstoffe und ihre ökotoxikologische Relevanz für den Bodensee. Euregio Ökotoxikologie Service Labor, im Auftrag der IGKB; 2002

7 Pfluger P, Wasserrab B, O Brien EO, Prietz A, Spengler P, Schneider C, Heußner A, Schmid T, Knörzer B, Metzger JW, Dietrich DR: Entwicklung und Validierung von in vitro Prüfsystemen zum Nachweis von endokrin wirksamen Fremdstoffen: Chemisch-analytische Überprüfung und biologische Wirkung von potentiell endokrin wirksamen Substanzen in Kläranlagenausläufen bzw. Vorflutern. Programm Lebensgrundlage Umwelt und ihre Sicherung (BWPLUS). Baden-Württemberg; (Förderkennzeichen PAÖ Ö-98004) 2001.

8 Rossknecht H, Hetzenauer H: Zum Vorkommen von ArzneimittelRückständen im Bodensee-Obersee und in einigen BadenWürttembergischen Bodenseezuflüssen. LFU/ISF, ISSN 1437-0166 (Bd.1); 2000

9 Streichfuss D, Brauch HJ, Fleig M, Hoheisel K: Komplexbildner in der Schussen. Final Report UBR-Project II U 14; 2000.

10 Auerbach B, Güde H, Miller G, Wurm K, Vogel HJ: „Schussenprogramm Erfolgskontrolle und Maßnahmenoptimierung. Abschlussbericht. Regierungspräsidium Tübingen; 2008

11 Rossknecht H: Die Entwicklung der NTA- und EDTA-Konzentrationen im Bodensee und in einigen Bodensee-Zuflüssen von 1985-1990. /GKB-Bericht Nr. 41: 1991
12 Hetzenauer H: Vermerk zu PFT-Untersuchungen im Bodensee und seinen Zuflüssen. LUBW intern, unveröffentlicht; 2008

13 Metzger JM, Möhle E: Flammschutzmittel in Oberflächenwässern, Grundwässern und Abwässern. Eintragspfade und Gehalte. Endbericht BW-Plus. FKZ BWB 99012; 2001

14 Kuch B, Körner W, Hagenmaier H: Monitoring von bromierten Flammschutzmitteln in Fließgewässern, Abwässern und Klärschlämmen in Baden-Württemberg. BW-Plus-Abschlussbericht. FKZ BWB 99011; 200

15 EU: Mitteilung der Kommission an das Europäische Parlament gemäß Artikel 251 Absatz 2 Unterabsatz 2 EG-Vertrag zu dem vom Rat festgelegten gemeinsamen Standpunkt im Hinblick auf den Erlass einer Richtlinie des Europäischen Parlaments und des Rates über Umweltqualitätsnormen im Bereich der Wasserpolitik und zur Änderung der Richtlinien 82/176/EWG, 83/513/EWG, 84/156/EWG, 84/491/EWG, 86/280/EWG und 2000/60/EG; KOM (2007) 871; 2008.

16 PAN-Pesticide Database, Pesticide Action Network, North America [http:// www.pesticideinfo.org]

17 Bro-Rasmussen F (Hrsg): EEC Water Quality Objectives for Chemicals Dangerous to Aquatic Environments (List 1). Reviews of Environmental Contamination and Toxicology 1994, 137:83-110.

18 Herrchen M, Müller M, Storm A: Ableitung von Zielvorgaben für prioritäre Stoffe zum Schutz von Oberflächengewässern. Abschlussbericht Umweltbundesamt, Berlin. F+E-Vorhaben 29724 309/02; 2000.

19 Hommen U, Schäfers C, Roß-Nickoll M, Ratte T: Auswertung der wichtigsten in Deutschland durchgeführten Monitoringstudien. Endbericht BVL zU Auswirkungen von Pflanzenschutzmitteln auf Nichtzielorganismen, 2004.

20 IKSR: Internationale Kommission zum Schutze des Rheins. Statusbericht Rhein; 1993

21 IKSR: Internationale Kommission zum Schutze des Rheins. PLEN 5/98, unveröffentlicht; 1998

22 IKSR: Internationale Kommission zum Schutze des Rheins. Stoffdatenblatt, Zusammenfassung AZ 42-98d rev.24.10.99; 1999

23 Kussatz, C, Schudoma D, Throl C, Kirchhoff N, Rauert C: Zielvorgaben für Pflanzenschutzmittelwirkstoffe zum Schutz oberirdischer Binnengewässer. Texte 76/99. Herausgegeben von Umweltbundesamt Berlin; 1999.

24 Moltmann JF, Liebig M, Knacker T, Keller M, Scheurer M, Ternes T: Gewässerrelevanz endokriner Stoffe und Arzneimittel. Abschlussbericht Umweltbundesamt Berlin. FKZ 20524205; 2007

25 Nenzda M: Entwicklung von Umweltqualitätsnormen zum Schutz aquatischer Biota in Oberflächengewässern. Abschlussbericht Umweltbundesamt Berlin. F+E-Vorhaben UFOPLAN FKZ 202 24 276; 2003.

26 Van Wenzel AP, van Vlaardingen P: Maximum permissible concentrations and negligible concentrations for antifouling substances. Irgarol 1051, dichlofluanid, ziram, chlorothalonil and TCMTB. RIVM - Bilthoven. RIVM Rapport 601501008; 2001.

27 ARGE Elbe: Arzneistoffe in Elbe und Saale. BKH Consulting Engi Arbeitsgemeinschaft für die Reinhaltung der Elbe; 2003.

28 Bund/Länderausschuss für Chemikaliensicherheit (BLAC): Arzneimittel in der Umwelt, Auswertung der Untersuchungsergebnisse Bericht an die 61. UMK; 2002

29 BLAC: Arzneimittel in der Umwelt, Auswertung der Untersuchungsergebnisse. Bericht an die 61. Umweltministerkonferenz (UMK); 2003

30 Internationalen Arbeitsgemeinschaft der Wasserwerke im Rheineinzugsgebiet IAWR: Stellungnahme der IAWR zum Proposal for a directive of the European Parliament and of the Council on Environmental Quality Standards and Pollution Control in the Field of Water Policy and Amending Directive 2000/60/EC (Liste prioritärer Stoffe); 2005

31 Jahnel J, Neamtu M, Abbt-Braun G, Haak D, Gordalla B: Entwicklung von Umweltqualitätsnormen zum Schutz aquatischer Biota in Oberflächengewässern für flussgebietsspezifische Stoffe. Abschlussbericht Länderfinanzierungsprogramm „Wasser und Boden”. LAWA-Projekt Nr. O 10.03; 2003.

32 Jahnel J, Neamtu M, Schudoma D, Frimmel FH: Bestimmung von Umweltqualitätsnormen für potenziell gewässerrelevante Stoffe. Act Hydrochem Hydrobio/ 2006, 34(4):389-397.

33 Landesamt für Natur, Umwelt und Verbraucherschutz Nordrhein-Westfalen (LANUV): Eintrag von Arzneimitteln und deren Verhalten und Verbleib in der Umwelt. Literaturstudie LANUV-Fachbericht 2; 2007.

34 Landesumweltamt Brandenburg (LUA): Ökotoxikologische Bewertung von 
Humanarzneimitteln in aquatischen Ökosystemen. Studien und Tagungsberichte 2002, 39

35 Thompson A: The Fate and Removal of Pharmaceuticals during Sewage Treatment. PhD thesis. Cranfield University; 2005

36 Umweltbundesamt Wien (UBA Wien): Hormonwirksame Stoffe in Österreichs Gewässer - Ein Risiko? Forschungsbericht; 2003.

37 EU: Dibutyl Phthalate CAS No: 84-74-2 EINECS No: 201-557-4. Summary Risk Assessment Report Special Publication 1.01.66; 2003

38 EU: Vorschlag für eine Richtlinie des Europäischen Parlaments und des Rates über Umweltqualitätsnormen im Bereich der Wasserpolitik und zur Änderung der Richtlinie 2000/60/EG \{KOM(2006)398 endgültig\}. http:// ec.europa.eu/environment/water/waterdangersub/ pdf/com_2006_397_ de.pdf; 2006

39 LAWA: Zielvorgaben zum Schutz oberirdischer Binnengewässer, Band I: Teil I: Konzeption zur Ableitung von Zielvorgaben zum Schutz oberirdischer Binnengewässer vor gefährlichen Stoffen, Teil II: Erprobung der Zielvorgaben von 28 gefährlichen Wasserinhaltsstoffen in Fließgewässern. [ISBN 3-88961-214-8]; 1997.

40 Hillenbrand, Marscheider-Weidemann, Strauch, Heitmann (UBA): Forschungsvorhaben "Emissionsminderung für prioritäre und prioritäre gefährliche Stoffe der Wasserrahmenrichtlinie. Datenblatt 25: Octylphenol; 2006.

41 Internationale Kommission zum Schutz der Elbe (IKSE): Erster Bericht über die Erfüllung des "Aktionsprogramms Elbe". Magdeburg; 1998.

42 UBA: Wasser, Trinkwasser und Gewässerschutz. Qualitätsanforderungen. [http://www.umweltbundesamt.de/wasser/themen/ oberflaechengewaesser/ow_s2_2.htm]

43 Schudoma D: Ableitung von Zielvorgaben zum Schutz oberirdischer Binnengewässer für die Schwermetalle Blei, Cadmium, Chrom, Kupfer, Nickel, Quecksilber und Zink. Texte 52/94, Umweltbundesamt Berlin; 1994.

44 Beach SA, Newsted JL, Coady K, Giesy JP: Ecotoxicological Evaluation of Perfluorooctanesulfonate (PFOS). Rev Environ Contamin Toxicol 2006, 186:133-174.

45 Brooke D, Footitt A, Nwaogu TA: Environmental risk evaluation report: perfluorooctanesulphonate (PFOS). Environment Agency, Chemicals Assessment Section, Wallingford, UK; 2004

46 Honnen W, Rath K, Schlegel T, Schwinger A, Frahne D: Chemical analyses of water, sediment and biota in two small streams in Southwest Germany. $J$ Aquat Ecosyst Stress Recov 2001, 8:195-213.

47 Schlichtig B, Schüle E, Rott U: Eintrag von Pflanzenschutzmitteln in die Seefelder Aach. Wasser und Abfall 2001, 3:20-28.

48 Rott U, Schlichtig B: Eintrag von Pflanzenschutzmitteln (PSM) in Oberflächengewässer am Beispiel des Bodensee-Zuflusses Seefelder Aach". Untersuchungsprogramm 2002. LUBW Abschlussbericht; 2003.

49 Staatliches Umweltamt Münster (StUA): Untersuchungen zum Verbleib von Carbamazepin und anderen Arzneimittelwirkstoffen im Gewässersystem des Münsterlandes. Dez. 41/42; 2004.

50 Ternes T, Siegrist H, Joss A, von Gunten U: Eliminierung von Pharmaka in der Abwasserreinigung und der Trinkwasseraufbereitung: Möglichkeiten und Grenzen. Vortrag UFZ - Pharmaka in der aquatischen Umwelt, 7.9.2006 [http:// www.ufz.de/data/Nortrag_034549.pdf]; 2006.

51 Fent K, Weston AA, Caminada D: Ecotoxicology of human pharmaceuticals. Aquat Toxicol 2006, 76:122-159.

52 Fent K: Effects of pharmaceuticals to aquatic organisms. In Pharmaceuticals in the Environment. Kümmerer K. Hrsg. Berlin, New York: Springer Verlag; 2008:175-203.

53 Kümmerer K (Hrsg): Pharmaceuticals in the Environment: Sources, Fate, Effects and Risks. Berlin, New York: Springer Verlag; 2008

54 Sattelberger R: Arzneimittelrückstände in der Umwelt: Bestandsaufnahme und Problemdarstellung. Report no. R-162, Umweltbundesamt Wien; 1999.

55 Ferrari B, Mons R, Vollat B, Fraysse B, Paxeus N, Lo Giudice R, Pollio A, Garric J: Environmental risk assessment of six human pharmaceuticals: are the current environmental risk assessment procedures sufficient for the protection of the aquatic environment? Environ Toxicol Chem 2004. 23(5):1344-1354.

56 Hanisch B, Abbas B, Kratz W, Schüürmann G: Humanarzneimittel im aquatischen Ökosystem. Bewertungsansatz zur Abschätzung des ökotoxikologischen Risikos von Arzneimittelrückständen. UWSF - Z Umweltchem Ökotox 2004, 16:223-238.

57 Castiglioni S, Bagnati R, Fanelli R, Pomati F, Calamari D, Zuccato E: Removal of pharmaceuticals in sewage treatment plants in Italy. Environ Sci Technol
2006, 40:357-363.

58 Schulte-Oehlmann U, Oehlmann J, Püttmann W: Humanpharmakawirkstoffe in der Umwelt: Einträge, Vorkommen und der Versuch einer Bestandsaufnahme. UWSF - Z Umweltchem Ökotox 2007, 19(3):168-179.

59 Sacher F, Lochow E, Bethmann D, Brauch HJ: Vorkommen von Arzneimittelwirkstoffen in Oberflächengewässern. Vom Wasser 1998, 90:233-243.

60 Stumpf M, Ternes TA, Haberer K, Seel P, Baumann W: Nachweis von Arzneimittelrückständen in Kläranlagen und Fließgewässern. Vom Wasser 1996, 86:291-303.

61 Brauch HJ, Fleig M, Sacher F, Kühn W, Lindner K: In Der Rhein im Jahr 2001. Herausgegeben von DVGW-Technologiezentrum Wasser (TZW) / Arbeitsgemeinschaft Rhein-Wasserwerke. Karlsruhe / Köln; 2001:32-38,

62 Wiegel S, Harms H, Stachel B, Brockmeyer R, Schmidt R, Aulinger A, von Tuempling W: Arzneistoffe in Elbe und Saale. Herausgegeben von Arbeitsgemeinschaft für die Reinhaltung der Elbe; 2003.

63 Sacher F: Vorkommen von Arzneimittelrückständen in Grund- und Oberflächenwässern in Baden-Württemberg. In: Pharmaka und Hormone in der aquatischen Umwelt - eine Bedrohung? 2. Hydrochemisches und Hydrobiologisches Kolloquium am 14.03.2002. Stuttgarter Berichte zur Siedlungswasserwirtschaft. Herausgegeben von Forschungs- und Entwicklungsinstitut für Industrie- und Siedlungswasserwirtschaft sowie Abfallwirtschaft e. V. Stuttgart; 2002, 168:59-67.

64 Christian T, Schneider RJ, Färber HA, Skutlarek D, Meyer MT, Goldbach HE: Determination of antibiotic residues in manure, soil, and surface waters. Act Hydrochim Hydrobiol 2003, 31(1):36-44.

65 Färber HA, Skutlarek D, Exner M: Untersuchung von Krankenhausabwässern eines Universitätsklinikums, von kommunalem Abwasser sowie von Oberflächenwasser und Uferfiltraten auf Rückstände ausgewählter Antibiotika. Abschlussbericht zum Forschungsprojekt im Auftrag des Landesumweltamts NRW. LUA. NRW 112-1781/MZ 43/99 und LUA NRW 1121781/MZ2/2000. Herausgegeben von Institut für Hygiene und Öffentliche Gesundheit Universität Bonn; 2001, 1-131

66 Ternes,TA: Vorkommen von Pharmaka in Gewässern. Wasser \& Boden 2001, 53(4):9-14.

67 Robakowski H: Arzneimittelrückstände und endokrin wirkende Stoffe in der aquatischen Umwelt. Herausgegeben von Landesanstalt für Umweltschutz Baden-Württemberg. Karlsruhe; 2000, Band 8.

68 Cleuvers M: Aquatic ecotoxicity of pharmaceuticals including the assessment of combination effects. Toxicol Lett 2003, 142:185-194

69 Körner W, Bolz U, Triebskorn R, Schwaiger J, Negele RD, Marx A, Hagenemaie $\mathrm{H}$ : Steroid analysis and xenosteroid potentials in two small streams in southwest Germany. J Aquat Ecosyst Stress Recov 2001, 8:215-229.

70 Tremblay L, Van Der Kraak G: Use of a series of homologous in vitro and in vivo assays to evaluate the endocrine modulating actions of $\beta$-sitosterol in rainbow trout. Aquat Toxicol 1998, 43:149-162.

71 Kümmerer K: Resistance in the environment. J Antimicrobiol Chemother 2004, 54:311-320.

72 Schlüter A, Szczepanowski R, Tennstedt T, Pühler A: Analyse von AntibiotikaResistenzplasmiden aus kommunalen Abwasserkläranlagen. Bremer Kolloquium Produktionsintegrierte Wasser- / Abwassertechnik 2004. Pharmazeutische Reststoffe in Abwässern. Vorkommen Gefährdungspotenzial - Techniken zur Eliminierung. Institut für Umweltverfahrenstechnik (Hrsg.), Bremen, B69-B84; 2004

73 Kohnen, W., Schön-Hölz, K., Schwartz, T., Volkmann, H., Rissler, K., Wurz, A. Obst, U., Jansen, B: Vorkommen und Ausbreitung der Antibiotikaresistenz in der aquatischen Umwelt. Bremer Kolloquium Produktionsintegrierte Wasser- / Abwassertechnik 2004. Pharmazeutische Reststoffe in Abwässern. Vorkommen - Gefährdungspotenzial - Techniken zur Eliminierung. Institut für Umweltverfahrenstechnik (Hrsq.), Bremen, B51-B60; 2004

74 Triebskorn R, Casper H, Heyd A, Eikemper R, Köhler HR, Schwaiger J: Toxic effects of the non-steroidal anti-inflammatory drug diclofenac. Part II: Cytological effects in liver, kidney, gills and gut of rainbow trout (Oncorhynchus mykiss). Aquat Toxicol 2004, 68:151-166.

75 Triebskorn R, Casper H, Scheil V, Schwaiger J: Ultrastructural effects of pharmaceuticals (carbamazepine, clofibric acid, metoprolol, diclofenac) in rainbow trout (Oncorhynchus mykiss) and common carp (Cyprinus carpio). Analyt Bioanalyt Chem 2007, 387(4):1405-1416.

76 Czech P, Weber K, DietrichDR: Effects of endocrine modulating substances on reproduction in the hermaphroditic snail Lymnaea stagnalis. L Aquat Toxicol 2001, 53(2):103-114. 
77 Kümmerer K, Alexy R: Näher an der Realität: Wirkung und Elimination von Stoffkombinationen. Stuttgarter Berichte zur Siedlungswasserwirtschaft 2005 182:42-52.

78 Cleuvers M: Mixture toxicity of the anti-inflammatory drugs diclofenac, ibuprofen, naproxen, and acetylsalicylic acid. Ecotoxicol Environ Saf 2004, 59(3):309-315.

79 Flaherty CM, Dodson SI: Effects of pharmaceuticals on Daphnia survival, growth, and reproduction. Chemosphere 2005, 61:200-207.

80 Stockholm County Council: Environmentally classified pharmaceuticals. [http://www.janusinfo.se/imcms/servlet/GetDoc?meta_id=9759]; 2007

81 Fries E, Püttmann W: Occurrence and behaviour of 4-nonylphenol in river water of Germany. J Environ Monit 2003, 5:598 - 603.

82 Oehlmann J, Oetken M, Schulte-Oehlmann U: A critical evaluation of the environmental risk assessment for plasticizers in the freshwater environment in Europe, with special emphasis on bisphenol $A$ and endocrine disruption. Environ Res 2008, 108:140 - 149.

83 Forbes VE, Selck H, Palmqvist A, Aufderheide J, Warbritton R, Pounds N, Thompson R, van der Hoeven N, Caspers N: Does bisphenol a induce superfeminization in Marisa cornuarietis? Part I: Intra- and inter-laboratory variability in test endpoints. Ecotoxicol Environ Saf 2007, 66:309-318.

84 Forbes VE, Aufderheide J, Warbritton R, van der Hoeven N, Caspers N: Does bisphenol a induce superfeminization in Marisa cornuarietis? Part II: Toxicity test results and requirements for statistical power analyses. Ecotoxicol Environ Saf 2007, 66:319-325.

85 Gies A, Gottschalk C, Greiner P, Heger W, Kolossa M, Rechenberg B, Rosskamp E, Schroeter-Kermani C, Steinhäuser K, Throl C: Nachhaltigkeit und Vorsorge bei der Risikobewertung und beim Risikomanagement von Chemikalien. Teil II: Umweltchemikalien, die auf das Hormonsystem wirken. Belastungen, Auswirkungen, Minderungsstrategien. Texte 30/01. Herausgegeben von Umweltbundesamt Berlin; 2002.

86 Fleig M, Brauch HJ, Streichfuss D, Hoheisel K: Synthetische Komplexbildner und andere xenobiotische Stoffe in der Schussen. AWBR-Berichte 2000, 32:59-77.

87 Schmidt CK, Fleig M, Sacher F, Brauch HJ: Occurrence of aminopolycarboxylates in the aquatic environment of Germany. Environ Pollut 2004, 131:107-124

88 Kowalik C, Einax JW: Investigations of complexation reactions of metals in anthropogenically polluted waters by ultrafiltration. Vom Wasser 2000, 94:229-243.

89 Liu H, Zhang JF, Shen H, Wang XR, Wang, WM: Impact of copper and its EDTA complex on the glutathione-dependent antioxidant system in freshwater fish (Carassius auratus). Bull Environ Contam Toxicol 2005, 74(6):1111-1117.

90 EU: European Union Risk Assessment Report Tetrasodium ethylenediaminetetraacetate (NA, EDTA); 2004.

91 Hillenbrand T, Toussaint D, Böhm E, Fuchs S, Scherer U, Rudolphi A, Hoffmann M: Einträge von Kupfer, Zink und Blei in Gewässer und Böden - Analyse der Emissionspfade und möglicher Emissionsminderungsmaßnahmen. Texte 19/05. Herausgegeben von Umweltbundesamt Berlin; 2005.

92 Martin JW, Mabury SA, Sololmon KR, Muir DCG: Bioconcentration and tissue distribution of perfluorinated acids in rainbow trout (Oncorhynchus mykiss). Environ Toxicol Chem 2003, 22(1):196-204.

93 Jones PD, Hu W, De Coen W, Newsted JL, Giesy JP: Binding of perfluorinated fatty acids to serum proteins. Environ Toxicol Chem 2003, 22(11):2639-2649.

94 Döpke A, Leutert D, Mavromati F, Pfeifer T: Perfluorierte Verbindungen: Falscher Alarm oder berechtigte Sorge? Herausgegeben von Umweltbundesamt Berlin; 2007

95 MacDonald M, Warne AL, Stock NL, Mabury SA, Solomon KR, Sibley PK: Toxicity of perfluorooctane sulfonic acid and perfluorooctanoic acid to Chironomus tentans. Environ Toxicol Chem 2004, 23(9):2116-2123.

96 Hagenaars A, Knapen D, Meyer IJ, van der Ven K, Hoff P, De Coen W: Toxicity evaluation of Perfluorooctane sulfonate (PFOS) in the liver of common carp (Cyprinus carpio). Aquat Toxicol 2008, 88:155-163.

97 Liu C, Du Y, Zhou B: Evaluation of estrogenic activities and mechanism of action of perfluorinated chemicals determined by vitellogenin induction in primary cultured tilapia hepatocytes. Aquat Toxicol 2007, 85(4):267-277.

98 Manchester-Neesvig JB, Valters K, Sonzogni WC: Comparison of polybrominated diphenyl ethers (PBDEs) and polychlorinated biphenyls (PCBs) in Lake Michigan salmonids. Environ Sci Technol 2001, 35:1072-1077.

99 Brown SB., Adams BA, Cyr DG, Eales JG: Contaminant effects on the teleost fish thyroid. Env Tox Chem 2004, 23(7):1680-1701.

100 Murvoll KM, Skaare JU, Anderssen E, Jenssen BM: Exposure and effects of persistent organic pollutants in European shag (Phalacrocorax aristotelis) hatchlings from the coast of Norway. Environ Toxicol Chem 2006, 25(1):190-198

101 Martin PA, Mayne GJ, Bursian SJ, Tomy G, Palace V, Pekarik C, Smits J: Immunotoxicity of the commercial polybrominated diphenyl ether mixture de-71 in ranch mink (Mustela vison). Environ Toxicol Chem 2007, 26: 988-997.

102 Villeneuve DL, Kannan K, Priest BT, Giesy JP: In vitro assessment of potential mechanism-specific effects of polybrominated diphenyl ethers. Environ Toxicol Chem 2002, 21:2431-2433.

103 Wollenberger L, Dinan L, Breitholtz M: Brominated flame retardants: activities in a crustacean development test and in an ecdysteroid screening assay. Environ Toxicol Chem 2005, 24:400-407.

104 Rott U, Schlichtig B: Literaturstudie zur Wirkung von Pestiziden auf aquatische Organismen. LUBW Abschlussbericht; Februar 2002.

105 LUBW: Originalmessdaten LUBW Karlsruhe; 2007.

106 Davies PE, Cook LSJ, Goenarso D: Sublethal responses to pesticides of several species of Australian freshwater fish and crustaceans and rainbow trout. Environ Toxicol Chem 1994, 13:1341-1354.

107 Saglio P, Trijasse S: Behavioral responses to atrazine and diuron in goldfish. Arch Environ Contam Toxicol 1998, 35:84-491.

108 Bringolf RB, Belden JB, Summerfelt RC: Effects of atrazine on fathead minnow in a short-term reproduction assay. Environ Toxicol Chem 2004, 23(4):1019-1025

109 Forget-Leray J, Landriau I, Minier C, Leboulenger F: Impact of endocrine toxicants on survival, development, and reproduction of the estuarine copepod Eurytemora affinis (Poppe). Ecotoxicol Environ Saf 2005, 60(3):288-294

110 Chang LW, Toth GP, Gordon DA, Graham DW, Meier JR, Knapp CW, Denoyelles FJ Jr., Campbell S, Lattier DL: Responses of molecular indicators of exposure in mesocosms: common carp (Cyprinus carpio) exposed to the herbicides alachlor and atrazine. Environ Toxicol Chem 2005, 24:190-197.

111 Tierney KB, Singh CR, Ross PS, Kennedy CJ: Relating olfactory neurotoxicity to altered olfactory-mediated behaviors in rainbow trout exposed to three currently-used pesticides. Aquat Toxicol 2007, 81(1):55-67.

112 Suzawa M, Ingraham HA: The herbicide atrazine activates endocrine gene networks via non-steroidal NR5A nuclear receptors in fish and mammalian cells. PLOS ONE 2008, 3(5):2117.

113 Belfroid AC, van Drune M, Beek MA, Schrap SM, van Gestel CAM, van Hattum $B$ : Relative risks of transformation products of pesticides for aquatic ecosystems. Sci Tot Environ 1998, 222:167-183.

114 Takiguchi N, Tajima, T, Asayama K, Ikeda T, Kuroda A, Kato J, Ohtake H: Behavioral Responses of the Ciliated Protozoan Paramecium caudatum to 2,4 Dichlorophenoxyacetic Acid and Its Analogues. J Biosci Bioeng 2002, 93(4):416-420

115 Enrich-Prast A: Effect of Pesticides on Nitrification in Aquatic Sediment. Braz J Biol 2006, 66(2A):405-12.

116 Nebeker AV, Schuytema GS: Chronic Effects of the Herbicide Diuron on Freshwater Cladocerans, Amphipods, Midges, Minnows, Worms, and Snails. Arch Environ Contam Toxicol 1998, 35:441-446.

117 Bretaud S, Toutant JP, Saglio P : Effects of Carbofuran, Diuron, and Nicosulfuron on Acetylcholinesterase Activity in Goldfish (Carassius auratus). Ecotoxicol Environ Saf 2000, 47:117-124

118 Morgan MJ, Kiceniuk JW: Recovery of foraging behavior of atlantic salmon exposed to a simulated commercial application of fenitrothion. Environ Toxicol Chem 1991, 10:961-965.

119 De Peyster A, Long WF: Fathead Minnow Optomotor Response as a Behavioural Endpoint in Aquatic Toxicity Testing. Bull Environ Contam Toxicol 1993, 51:88-95.

120 Berrill M, Bertram S, Pauli B, Coulson D, Kolohon M, Ostrander D: Comparative sensitivity of amphibian tadpoles to single and pulsed exposures of the forest-use insecticide fenitrothion. Environ Toxicol Chem 1995, 14:1011-1018.

121 Choi J, Caquet T, Roche H: Multilevel effects of sublethal fenitrothion exposure in Chironomus riparius mg. (Diptera, Chironomidae) larvae. Env Tox Chem 2002, 21:2725-2730.

122 Traunspurger W, Schäfer $\mathrm{H}$, Remde A: Comparative investigation on the effect of an herbicide on aquatic organisms in single species tests and aquatic microcosms. Chemosphere 1996, 33(6):1129-1141.

123 Greulich K, Hoque ER, Pflugmacher S: Uptake, Metabolism, and Effects on Detoxification Enzymes of Isoproturon in Spawn and Tadpoles of Amphibians. Ecotoxicol Environ Saf 2002, 52(3): 256-266. 
124 Hurst MR, Sheahan DA: The potential for estrogenic effects of pesticides in headwater streams in the UK. Sci Tot Environ 2003, 301:87-96.

125 Schmitt-Jansen M, Altenburger R: Toxic effects of isoproturon on periphyton communities - a microcosm study. Estuarine, Coastal and Shelf Science 2005, 62:539-545.

126 Küster A, Altenburger R: Development and validation of a new fluorescence-based bioassay for aquatic macrophyte species. Chemosphere 2007, 67(1):194-201

127 Vallotton N, Eggen RIL, Chevre N: Effect of Sequential Isoproturon Pulse Exposure on Scenedesmus Vacuolatus. Arch Environ Contam Toxicol 2008, $1-8$

128 Dewez D, Didur O, Vincent-Heroux V, Popovic R: Validation of photosynthetic-fluorescence parameters as biomarkers for isoproturon toxic effect on alga Scenedesmus obliquus. Environ Pollut 2008, 151(1):93-100.

129 Desi I, Dura G, Gonczi L, Kneffel Z, Strohmayer A, Szabo Z : Toxicity of malathion to mammals, aquatic organisms and tissue culture cells. Arch Environ Contam Toxicol 1975, 3(4):410-425.

130 Cook LW, Paradise CJ, Lom B: The pesticide malathion reduces survival and growth in developing zebrafish. Environ Toxicol Chem 2005, 24:1745-1750.

131 Ren Z, Zha J, Ma M, Wang Z, Gerhardt A: The early warning of aquatic organophosphorus pesticide contamination by on-line monitoring behavioral changes of Daphnia magna. Environ Monit Assess 2007 134:373-383.

132 EU :European Commission Health \& Consumer Protection. Review report for the active substance mecoprop; 2003.

133 Hattula ML, Reunanen H, Arstila AU: The Toxicity of MCPA to Fish. Light and Electron Microscopy and the Chemical Analysis of the Tissue. Bull Environ Contamin Toxicol 1978, 19:465-470.

134 Woin P, Brönmark C: Effect of DDT and MCPA (4-Chloro-2Methylphenoxyacetic Acid) on Reproduction of the Pond Snail, Lymnaea stagnalis L. Bull Environ Contam Toxicol 1992, 48:7-13.

135 Johansson M, Piha H, Kylin H, Merila J: Toxicity of six pesticides to common frog (Rana temporaria) tadpoles. Environ Toxicol Chem 2006, 25:3164-3170.

136 Honrubia MP, Hemlez MP, Alvarez R: The Carbamate Insecticide ZZ-Aphox ${ }^{\circledR}$ Induced Structural Changes of Gills, Liver, Gall-Bladder, Heart, and Notochord of Rana perezi Tadpoles. Arch Environ Contam Toxicol 1993, 25:184-191.

137 Widenfalk A, Svensson JM, Goedkoop W: Effects of the pesticides captan, deltamethrin, isoproturon, and pirimicarb on the microbial community of a freshwater sediment. Environ Toxicol Chem 2004, 23:1920-1927.

138 Levine SL, Oris JT, Denison MS: Modulation of cyp1a expression in rainbow trout by a technical grade formulation of propiconazole. Environ Toxicol Chem 1999, 18:2565-2573.

139 Kast-Hutcheson KK, Rider CV, Leblanc GA: The fungicide propiconazole interferes with embryonic development of the crustacean Daphnia magna. Environ Toxicol Chem 2001, 20:502-509.

140 Wu C, Riise G, Pflugmacher S, Greulich K, Steinberg CEW: Combined effects of the fungicide propiconazole and agricultural runoff sediments on the aquatic bryophyte Vesicularia dubyana. Env Toxicol Chem 2005, 24:2285-2290

141 Bringolf RB, Cope WG, Eads CB, Lazaro PL, Barnhart MC, Shea D: Acute and chronic toxicity of technical-grade pesticides to glochidia and juveniles of freshwater mussels (Unionidae). Env Tox Chem 2007, 26:2086-2093.

142 Wilson PC, Whitwell T, Klaine SJ: Phytotoxicity, uptake, and distribution of $\left[{ }_{14} \mathrm{C}\right]$ simazine in Canna hybrida 'yellow king humbert". Environ Toxicol Chem 1998, 18(7):1462-1468

143 Dodson JJ, Mayfield Cl: Modification of the rheotropic response of rainbow trout (Salmo gairdneri) by sublethal doses of the aquatic herbicides Diquat and Simazine. Environ Pollut 1979, 18(2):147-157.

144 Arufe MI, Arellano J, Moreno, MJ, Sarasquete C: Comparative Toxic Effects of Formulated Simazine on Vibrio fischeri and Gilthead Seabream (Sparus aurata L.) Larvae. Chemosphere 2004, 57(11):1725-1732

145 Moore A, Lower N: The Impact of Two Pesticides on Olfactory-Mediated Endocrine Function in Mature Male Atlantic Salmon (Salmo salar L.) Parr. Comp Biochem Physiol B 2001, 129(2/3):269-276

146 Brust K, Licht O, Hultsch V, Jungmann D, Nagel R: Effects of terbutryn on aufwuchs and Lumbriculus variegatus in artificial indoor streams. Environ Toxicol Chem 2001, 20:2000-2007.

147 Rioboo C, Prado R, Herrero C, Cid A: Population growth study of the rotifer Brachionus sp. fed with triazine-exposed microalgae. Aquat Toxicol 2007.
83:247-253.

148 Pfluger P, Prietz A, Wasserrab B, Koster C, Knörzer B, Dietrich D: Untersuchungen zur aquatischen Toxizität und zur endokrinen Aktivität von Carbamazepin. Abschlussbericht ISF, LUBW 2000.

149 Ferrari B, Paxeus N, Lo Guidice R, Pollio A, Garric J: Ecotoxicological impact of pharmaceuticals found in treated wastewaters: Study of carbamazepine, clofibric acid and diclofenac. Ecotox Environ Saf 2003, 55:359-370.

150 Schwaiger J, Negele RD: Ökotoxikologische Auswirkungen von Arzneimitteln. Langzeitwirkungen bei Fischen. Abschlussbericht des Bayerischen Landesamtes für Wasserwirtschaft zum Forschungs- und Entwicklungsvorhaben 2001-2003; 2004

151 Liebig M: Untersuchungen zu Umweltrisikoabschätzungen von Humanpharmaka und Inhaltsstoffen von Körperpflegeprodukten vor dem Hintergrund europäischer Bewertungskonzepte. Dissertation. JohannWolfgang-Goethe-Universität, Frankfurt am Main; 2005.

152 Lai HT, Hou JH, Su Cl, Chen CL: Effects of chloramphenicol, florfenicol, and thiamphenicol on growth of algae Chlorella pyrenoidosa, Isochrysis galbana, and Tetraselmis chui. Ecotox Environ Saf 2008, im Druck

153 Isidori M, Lavorgna M, Nardelli A, Pascarella L, Parrella A: Toxic and genotoxic evaluation of six antibiotics on non-target organisms. Sci Tot Environ 2005, 346:87-98.

154 Schwaiger J, Ferling H, Mallow U, Wintermayr H, Negele RD: Toxic effects of the non-steroidal anti-inflammatory drug diclofenac. Part I. Histopathological alterations and bioaccumulation in rainbow trout. Aquat Toxicol 2004, 68(2):141-150.

155 Xue RD, Barnard DR, Ali A: Laboratory toxicity of three mosquito oviposition repellents to six nontarget aquatic invertebrates. Environ Entomol 2000, 29:437-441

156 Purdom CE, Hardiman PA, Bye WJ, Eno NC, Tyler CR, Sumpter JP: Estrogenic effects of effluents from sewage treatment works. Chem Ecol 1994, 8(4):275-285.

157 Wenzel A, Schmitz A, Schäfers C, Böhmer W: Nebenwirkungen von. Kontrazeptiva - Umweltrelevante Konzentrationen von Ethinylestradiol beeinträchtigen die Befruchtungsfähigkeit von Fischen. Jahresbericht 1999 -IUCT Fraunhofer Institut für Umweltchemie und Ökotoxikologie 1999, 49-52.

158 Länge R, Hutchinson TH, Croudace CP, Siegmund F, Schweinfurth H, Hampe P, Panter GH, Sumpter JP: Effects of the synthetic estrogen 17 alphaethinylestradiol on the life-cycle of the fathead minnow (Pimephales promelas). Environ Toxicol Chem 2001, 20(6):1216-27.

159 Panter GH, Hutchinson TH, Länge R, Lye CM, Sumpter JP, Zerulla M, Tyler CR: Utility of a juvenile fathead minnow screening assay for detecting antiestrogenic substances. Environ Toxicol Chem 2002, 21(2):319-26.

160 Watts MM, Pascoe D, Carroll K: Population responses of the freshwater amphipod Gammarus pulex (L.) to an environmental estrogen, 17alphaethinylestradiol. Environ Toxicol Chem 2002, 21(2):445-50

161 Jobling S, Casey D, Rodgers-Gray T, OehImann J, Schulte-Oehlmann U, Pawlowski S, BaunbeckT, Turner AP, Tyler CR: Comparative responses of molluscs and fish to environmental estrogens and an estrogenic effluent. Aquat Toxicol 2003, 65(2):205-220.

162 Segner H, Fenske CM, Janssen CR, Maack G, Pascoe D, Schaefers C, Vandenbergh GF, Watts M, Wenzel A: Identification of endocrine-disrupting effects in aquatic vertebrates and invertebrates: report from the European IDEA project. Ecotox Environ Saf 2003, 54: 302-314.

163 Thomas-Jones E, Thorpe K, Harrison N, Thomas G, Morris C, Hutchinson T, Woodhead S, Tyler C: Dynamics of estrogen biomarker responses in rainbow trout exposed to 17beta-estradiol and 17alpha-ethinylestradiol. Environ Toxicol Chem 2003, 22(12):3001-8.

164 Nash JP, Kime DE, Van der Ven LTM, Wester PW, Brion F, Maack G, Stahlschmidt-Allner $P$, Tyler CR: Long-term exposure to environmental concentrations of the pharmaceutical ethinylestradiol causes reproductive failure in fish. Environ Health Perspect 2004, 112(17):1725-1733.

165 Weber LP, Balch GC, Metcalfe CD, Janz DM: Increased kidney, liver, and testicular cell death after chronic exposure to 17alpha-ethinylestradiol in medaka (Oryzias latipes). Environ Toxicol Chem 2004, 23(3): 792-7.

166 Parrott JL, Blunt BR: Life-cycle exposure of fathead minnows (Pimephales promelas) to an ethinylestradiol concentration below $1 \mathrm{ng} / \mathrm{L}$ reduces egg fertilization success and demasculinizes males. Environ Toxicol 2005, 20(2):131-41.

167 Kiparissis Y, Balch GC, Metcalfe TL, Metcalfe CD: Effects of the isoflavones genistein and equol on the gonadal development of Japanese medaka Oryzias latipes. Environ Health Perspect 2003, 11(9):1158-63. 
168 Ingham RR, Gesualdi DA, Toth, CR, Clotfelter ED: Effects of genistein on growth and development of aquatic vertebrates. Bull Environ Contam Toxicol 2004, 72(3):625-31.

169 Seki M, Yokota H, Maeda M, Kobayashi K: Fish full life-cycle testing for 17beta-estradiol on medaka (Oryzias latipes). Environ Toxicol Chem 2005, 24(5):1259-66.

170 Filby AL, Thorpe KL, Tyler CR: Multiple molecular effect pathways of an environmental oestrogen in fish. J Mol Endocrinol 2006, 37(1):121-34.

171 Seki M, Fujishima S, Nozaka T, Maeda M, Kobayashi K: Comparison of response to 17-beta-estradiol and 17 beta-trenbolone among three small fish species. Environ Toxicol Chem 2006, 25(10):2742-52

172 Van der Ven LT, van den Brandhof EJ, Vos JH, Wester PW: Effects of the estrogen agonist 17 beta-estradiol and antagonist tamoxifen in a partial life-cycle assay with zebrafish (Danio rerio). Environ Toxicol Chem 2007 26(1):92-9. Erratum in: Environ Toxicol Chem 2007, 26(2):380.

173 Bjerregaard P, Hansen PR, Larsen KJ, Erratico C, Korsgaard B, Holbech H: Vitellogenin as a biomarker for estrogenic effects in brown trout, Salmo trutta: laboratory and field investigations. Environ Toxicol Chem 2008, 27(11):2387-2396

174 Lehtinen KJ, Mattsson K, Tana J, Engström C, Lerche O, Hemming J: Effects of wood-related sterols on the reproduction, egg survival, and offspring of brown trout (Salmo trutta lacustris L.). Ecotoxicol Environ Saf 1999, 42(1):40-9.

175 Honkanen JO, Kostamo A, Kukkonen JV: Toxicity of a phytosterol mixture to grayling (Thymallus thymallus) during early developmental stages. Arch Environ Contam Toxicol 2005, 48(3):391-6.

176 Brain RA, Johnson DJ, Richards SM, Sanderson H, Sibley PK, Solomon KR: Effects of 25 pharmaceutical compounds to Lemna gibba using a sevenday static-renewal test. Environ Toxicol Chem 2004, 23(2): 371-382.

177 Kolpin DW, Furlong ET, Meyer MT, Thurman EM, Zaugg SD, Barber LB, Buxton HT: Pharmaceuticals, hormones, and other organic wastewater contaminants in U.S. streams, 1999-2000: A national reconnaissance. Environ Sci Technol 2002, 36(6):1202-1211.

178 Oehlmann J, Schulte-Oehlmann U, Tillmann M, Markert B: Effects of Endocrine Disruptors on Prosobranch Snails (Mollusca: Gastropoda) in the Laboratory. Part I: Bisphenol A and Octylphenol as Xeno-Estrogens. Ecotoxicology 2000, 9:383-397.

179 Sohoni P, Tyler CR, Hurd KS, Caunter JE, Hetheridge MJ, Williams TD, Woods C, Evans M, Toy R, Gargas M, Sumpter JP: Reproductive effects of long-term exposure to Bisphenol $A$ in the fathead minnow (Pimephales promelas). Environ Sci Technol 2001, 35:2917-2925

180 Hahn T, Schenk K, Schulz R: Environmental chemicals with known endocrine potential affect yolk protein content in the aquatic insect Chironomus riparius. Environ Pollut 2002, 120:525-528.

181 Pascoe D, Carroll K, Karntanut W, Watts MM : Toxicity of 17a-ethinylestradiol and bisphenol A to the freshwater cnidarian Hydra vulgaris. Arch Environ Contam Toxicol 2002, 43:56-63.

182 Van der Hoeven N: Experiments on the effect of BPA on the snail species Marisa cornuarietis as described in three papers by Oehlmann: Evaluation of the applied statistics and analysis of the raw data. ECOSTAT Report 05/011, 14 October 2005

183 Oehlmann J, Schulte-Oehlmann U, Bachmann J, Oetken M, Lutz I, Kloas W, Ternes TA: Bisphenol A induces superfeminization in the ramshorn snail Marisa cornuarietis(Gastropoda: prosobranchia) at environmentally relevant concentrations. Environ Health Perspect 2006, 114(Suppl 1):127-133.

184 Forbes VE, Warbritton R, Aufderheide J, van der Hoeven N, Caspers N: Effects of bisphenol on fecundity, egg hatchability, and juvenile growth of Marisa cornuarietis. Environ Toxicol Chem 2008, 27(11):2232-2240.

185 Toussaint MW, Rosencrance AB, Brennan LM, Dennis WE, Beaman JR, Wolfe MJ, Hoffmann FJ, Gardner HS: Chronic toxicity of bromodichloromethane to the Japanese medaka (Oryzias latipes).Toxicol Pathol 2001, 29(6): 662-669.

186 Schwaiger J, Spieser OH, Bauer C, Ferling H, Mallow U, Kalbfus W, Negele RD: Chronic toxicity of nonylphenol and ethinylestradiol: haematological and histopathological effects in juvenile Common carp (Cyprinus carpio). Aquat Toxicol 2000, 51(1):69-78

187 Schwaiger J, Mallow U, Ferling H, Knoerr S, Braunbeck T, Kalbfus W, Negele $\mathrm{RD}$ : How estrogenic is nonylphenol? A transgenerational study using rainbow trout (Oncorhynchus mykiss) as a test organism. Aquat Toxicol 2002, 59(3-4):177-89.

188 Seki M, Yokota H, Maeda M, Tadokoro H, Kobayashi K: Effects of 4-nonylphenol and 4-tert-octylphenol on sex differentiation and vitellogenin induction in medaka (Oryzias latipes). Environ Toxicol Chem 2003, 22(7):1507-1516

189 Lahnsteiner F, Berger B, Grubinger F, Weismann T: The effect of 4-nonylphenol on semen quality, viability of gametes, fertilization success, and embryo and larvae survival in rainbow trout (Oncorhynchus mykiss). Aquat Toxicol 2005, 71(4): 297-306.

190 Lee SB, Choi J: Multilevel evaluation of nonylphenol toxicity in fourthinstar larvae of Chironomus riparius (Diptera, Chironomidae). Environ Toxicol Chem 2006, 25(11):3006-3014.

191 Schubert S, Peter A, Burki R, Schönenberger R, Suter,MJ, Segner H, BurkhardtHolm P: Sensitivity of brown trout reproduction to long-term estrogenic exposure. Aquat Toxicol 2008, 90(1):65-72.

192 Jobling S, Sheahan D, Osborne JA, Matthiessen P, Sumpter JP: Inhibition of testicular growth in rainbow trout (Oncorhynchus mykiss) exposed to estrogenic alkylphenolic chemicals. Environ Toxicol Chem 1996, 15:194-202.

193 Andersen HR, Wollenberger L, Halling-Sorensen B, Kusk KO: Development of copepod nauplii to copepodites-a parameter for chronic toxicity including endocrine disruption. Environ Toxicol Chem 1996, 20(12):2821-2829.

194 Karels AA, Manning S, Brouwer TH, Brouwer M: Reproductive effects of estrogenic and antiestrogenic chemicals on sheepshead minnows (Cyprinodon variegatus). Environ Toxicol Chem 2003, 22(4):855-865.

195 Sillanpää M: Environmental fate of EDTA and DTPA. Rev Environ Contam Toxicol 1997, 152:85-111.

196 Van Dam RA, Barry MJ, Ahokas JT, Holdway DA: Comparative acute and chronic toxicity of diethlenetriamine pentaacetic acid (DTPA) and ferriccomplexed DTPA to Daphnia carinata. Arch Environ Contam Toxicol 1996, 31:433- 443

197 Van Dam RA, Ahokas JT, Holdway DA: Chronic toxicity of diethylenetriamine pentaacetic acid to crimson-spotted rainbow fish (Melanotaenia fluviatilis): Effects on reproduction, condition, and ethoxyresorufin Odeethylase activity. Ecotox Environ Saf 1999, 43:74-82.

198 Sillanpää M, Oikari A: Assessing the impact of complexation by EDTA and DTPA on heavy metal toxicity using microtox bioassay. Chemosphere 1996, 32:1485-1497.

199 Verschueren K: Handbook of environmental data on organic chemicals. New York: John Wiley \& Sons; 2001, 2391 pp.

200 Canton JH, Slooff W: Substitutes for phosphate containing washing products: their toxicity and biodegradability in the aquatic environment. Chemosphere 1982, 11:891-907.

201 Arthur JW, Lemke AE, Mattson VR, Halligan BJ: Toxicity of sodium nitrilotriacetate (NTA) to the fathead minnow and amphipod in soft water. Wat Res 1974, 8:187-193.

202 Sellin MK, Kolok AS: Cd exposures in fathead minnows: effects on adult spawning success and reproductive physiology. Arch Environ Contamin Toxicol 2006, 51(4): 594-599203 Kusch RC, Krone PH, Chivers DP: Chronic exposure to low concentrations of waterborne cadmium during embryonic and larval development results in the long-term hindrance of antipredator behavior in zebrafish. Environ Toxicol Chem 2007, 27(3):705-10.

204 Besser JM, Mebane CA, Mount DR, Ivey CD, Kunz JL, Greer IE, May TW, Ingersoll CG: Sensitivity of mottled sculpins (Cottus bairdi) and rainbow trout (Oncorhynchus mykiss) to acute and chronic toxicity of cadmium, copper, and zinc. Environ Toxicol Chem 2007, 26(8):1657-1665.

205 Brinkman SF, Hansen DL: Toxicity of cadmium to early life stages of brown trout (Salmo trutta) at multiple water hardnesses. Environ Toxicol Chem 2007, 26(8):1666-1671.

206 Gross JA, Chen TH, Karasov WH: Lethal and sublethal effects of chronic cadmium exposure on northern leopard frog (Rana pipiens) tadpoles. Environ Toxicol Chem 2007, 26(6):1192-1197.

207 Asagba SO, Eriyamremu GE, Igberaese ME: Bioaccumulation of cadmium and its biochemical effect on selected tissues of the catfish (Clarias gariepinus). Fish Physiol Biochem 2008, 34(1):61-69.

208 Nebeker AV, Savonen C, Baker RJ, McCrady JK: Effects of copper, nickel and zinc on the lifecycle of the caddisfly clistoronia magnifica (Limnephilidae) Environ Toxicol Chem 1984, 3:645-649.

209 Dave G Xiu R: Toxicity of mercury, copper, nickel, lead, and cobalt to embryos and larvae of zebrafish, Brachydanio rerio. Arch Environ Contam Toxicol 1991, 21(1):126-134.

210 Craig PM, Wood CM, McClelland GB: Oxidative stress response and gene expression with acute copper exposure in zebrafish (Danio rerio). Am J Physiol Regul Integr Comp Physiol 2007, 293(5):1882-1892. 
211 Moreira-Santos M, Donato C, Lopes I, Ribeiro: Avoidance tests with small fish: determination of the median avoidance concentration and of the lowest-observed-effect gradient. Environ Toxicol Chem 2008, 27(7):1576-1582.

212 Kamunde C, MacPhail R, Mahar D, Grimmelt B: Evaluation of antioxidant circulatory lipid-soluble vitamins and sodium as non-invasive indicators of chronic copper exposure and toxicity in rainbow trout, Oncorhynchus mykiss. Bull Environ Contam Toxicol 2008, 80(6):502-506.

213 Knakievicz T, Ferreira HB: Evaluation of copper effects upon Girardia tigrina freshwater planarians based on a set of biomarkers. Chemosphere 2008 71(3):419-28.

214 Nebeker A, Savonen C, Stevens D: Sensitivity of rainbow trout early life stages to nickel chloride. Environ Toxicol Chem 1985, 4:233 - 239.

215 Kienle C, Köhler HR, Filser J, Gerhardt A: Effects of nickel chloride and oxygen depletion on behaviour and vitality of zebrafish (Danio rerio, Hamilton, 1822) (Pisces, Cypriniformes) embryos and larvae. Environ Poll 2007, 152(3):612-620.

216 Senatori O, Setini A, Scirocco A, Nicotra A: Effect of short-time exposures to nickel and lead on brain monoamine oxidase from Danio rerio and Poecilia reticulate. Env Toxicol 2008, publ. online first.

217 Woodling J, Brinkman S, Albeke S: Acute and chronic toxicity of zinc to the mottled sculpin Cottus bairdi. Environ Toxicol Chem 2002, 21(9):1922-1926.

218 Aït-Aïssa S, Ausseil O, Palluel O, Vindimian E, Garnier-Laplace J, Porcher JM: Biomarker responses in juvenile rainbow trout (Oncorhynchus mykiss) after single and combined exposure to low doses of cadmium, zinc, PCB77 and 17beta-oestradiol. Biomarkers 2003, 8(6):491-508.

219 Ji K, Kim Y, Oh S, Ahn B, Jo H, Choi K: Toxicity of perfluorooctane sulfonic acid and perfluorooctanoic acid on freshwater macroinvertebrates
(Daphnia magna and Moina macrocopa) and fish (Oryzias latipes). Environ Toxicol Chem 2008, 27(10):2159-2168.

220 Martin JW, Oakes K, Van der Kraak G, Sololmon KR, Mabury S, Muir DCG: Toxic effects and tissue distribution of perfluoroctanestersulfonates in rainbow trout. SETAC Baltimore, 2001; Abstract 283.

221 Boudreau TM, Sibley PK, Mabury SA, Muir DCG, Solomon KR: Laboratory evaluation of the toxicity of perfluorooctane sulfonate (PFOS) on Selenastrum capricornutum, Chlorella vulgaris, Lemna gibba, Daphnia magna and Daphnia pulicaria. Arch Environ Contam Toxicol 2003, 44:307-313.

222 Breitholtz M, Wollenberger L: Effects of three PBDEs on development reproduction and population growth rate of the harpacticoid copepod Nitocra spinipes. Aquat Toxicol 2003, 64(1):85-967.

223 Nakari T, Huhtala S: Comparison of toxicity of congener-153 of PCB, PBB, and PBDE to Daphnia magna. Ecotox Env Saf 2008, 71(2):514-518.

224 Key PB, Chung KW, Hoguet J, Shaddrix B, Fulton MH: Toxicity and physiological effects of brominated flame retardant PBDE-47 on two life stages of grass shrimp, Palaemonetes pugio. Sci Tot Environ 2008, 399(1-3):28-32

doi:10.1186/2190-4715-23-8

Cite this article as: Triebskorn $\mathrm{R}$, Hetzenauer $\mathrm{H}$ : Micropollutants in three tributaries of Lake Constance, Argen, Schussen and Seefelder Aach: a literature review. Environmental Sciences Europe 2012, 24:8. 